\title{
Preparation, Properties, and Self-Assembly Behavior of PTFE-Based Core-Shell Nanospheres
}

\author{
Katia Sparnacci, ${ }^{1}$ Diego Antonioli, ${ }^{1}$ Simone Deregibus, ${ }^{1}$ Michele Laus, ${ }^{1}$ \\ Giampaolo Zuccheri, ${ }^{2}$ Luca Boarino, ${ }^{3}$ Natascia De Leo, ${ }^{3}$ and Davide Comoretto ${ }^{4}$ \\ ${ }^{1}$ Dipartimento di Scienze dell' Ambiente e della Vita, Università del Piemonte Orientale “A. Avogadro”, INSTM, \\ UdR Alessandria, Via G. Bellini 25 g, 15100 Alessandria, Italy \\ ${ }^{2}$ Dipartimento di Biochimica "G. Moruzzi”, Università di Bologna, INSTM, CNRNANO-S3, Via Irnerio 48, 40126 Bologna, Italy \\ ${ }^{3}$ NanoFacility Piemonte, Electromagnetism Division, Istituto Nazionale di Ricerca Metrologica \\ Strada delle Cacce 91, 10135 Torino, Italy \\ ${ }^{4}$ Dipartimento di Chimica e Chimica Industriale, Università degli Studi di Genova, Via Dodecaneso 31, 16146 Genova, Italy
}

Correspondence should be addressed to Michele Laus, michele.laus@mfn.unipmn.it

Received 2 August 2011; Revised 17 October 2011; Accepted 24 October 2011

Academic Editor: Hai-Sheng Qian

Copyright ( $) 2012$ Katia Sparnacci et al. This is an open access article distributed under the Creative Commons Attribution License, which permits unrestricted use, distribution, and reproduction in any medium, provided the original work is properly cited.

\begin{abstract}
Nanosized PTFE-based core-shell particles can be prepared by emulsifier-free seed emulsion polymerization technique starting from spherical or rod-like PTFE seeds of different size. The shell can be constituted by the relatively high Tg polystyrene and polymethylmethacrylate as well as by low Tg polyacrylic copolymers. Peculiar thermal behavior of the PTFE component is observed due to the high degree of PTFE compartmentalization. A very precise control over the particle size can be exerted by properly adjusting the ratio between the monomers and the PTFE seed. In addition, the particle size distribution self-sharpens as the ratio monomer/PTFE increases. Samples with uniformity ratios suited to build 2D and 3D colloidal crystals are easily prepared. In particular, 2D colloidal crystal of spheres leads to very small 2D nanostructuration, useful for the preparation of masks with a combination of nanosphere lithography and reactive ion etching. 3D colloidal crystals were also obtained featuring excellent opal quality, which is a direct consequence of the monodispersity of colloids used for their growth.
\end{abstract}

\section{Introduction}

A milestone in the tetrafluoroethylene (TFE) polymerization is represented by the development of the homo- and copolymerization microemulsion technology, on industrial scale, based on the use of perfluoropolyethers (PFPE) in oil/water microemulsion. A great deal of interest was focused on the resulting polytetrafluoroethylene (PTFE) nano- and microparticle latexes $[1,2]$. PTFE aqueous dispersions featuring particle size as small as $10 \mathrm{~nm}$ can be produced, with particle concentration number as high as $10^{18}-10^{19}$ (particles/liter) Moreover, by varying the amount and structure of PFPE as well as the quantity and nature of the comonomers, PTFE nanoparticles can be designed with highly differentiated architectures, including size, shape, and chemical composition.
Many interesting applications were disclosed for these PTFE nanoparticles including components in PTFE bimodal mixtures, ultralow-K dielectric materials, nanofillers for fluoroelastomers and fire-retardant additives with the reported purpose to inhibiting the dripping of molten particles from the burning polymer [3-6].

However, the compatibility and adhesion characteristics of PTFE and the various polymeric matrices are inadequate thus resulting in low dispersion degrees within the matrix and poor mechanical coupling among the various blend components. Moreover, the resulting compositions exhibit a pearl scent opaque appearance that prevents their use in applications where transparency is required. Finally, the poor dispersion of PTFE material adversely affects the efficiency in reducing the heat release. 
To enhance wettability and compatibility, several PTFE surface modification strategies were developed based on either high power chemical and reactive processing procedures $[7,8]$ or high energy treatments $[9,10]$. Reactive extrusion of electron-beam irradiated PTFE and polyamides was demonstrated [11-13] to be effective in the preparation of well-dispersed compounds due to the occurrence of transamidation reactions accompanied by the breakdown of the PTFE agglomerates. However, consistent degradation of the basic PTFE structure upon irradiation is unavoidable.

An alternative and promising nondestructive approach to produce compounds with a perfect dispersion of PTFE particles is based on the preparation of core-shell particles in which the core is constituted by PTFE and the shell by a conventional polymer. In the early studies, several composite particles consisting of PTFE core and crosslinked polybutadiene shell were described by Okaniwa [14] whereas the preparation of one sample only of core-shell particles in which the core is made up of PTFE and the shell of crosslinked PS was reported by Othegraven [15]. More recently, extensive studies were reported for core-shell nanoparticle systems composed of PTFE core and polyacrylic shell $[16,17]$ with various compositions.

Two-stage seeded emulsion polymerization is the general method $[18,19]$ to prepare latex particles featuring a coreshell morphology. The first stage, the core preparation, can be carried out either separately or in situ and the polymerization process of the second stage is a seeded process in which the second monomer is added continuously or batchwise to the reaction vessel. In most cases, some miscibility between the core polymer and the shell-forming monomer produces a partial swelling thus ultimately leading to an intermixing diffuse region. However, in the present case, the shell-forming monomer is always insoluble in the PTFE and the polymerization occurs exclusively in the shell region of the latex.

A perfect degree of dispersion of the PTFE particles within a polymer matrix could be obtained if the shell is constituted by the same polymeric material with which the polymer matrix is made up. The application of this concept leads to a novel class of specific and very efficient PTFE-based additives (Scheme 1).

An additional reason of interest for these core-shell nanoparticles is also related to their potential use as building blocks for colloidal crystals and other nanostructured materials [20-23]. They can self-assemble to generate 2D and $3 \mathrm{D}$ ordered structures which represent promising candidates in applications such as catalysis, sensing, optics, molecular separation, molecular reaction dynamics, single-molecule detection, and optoelectronics.

Two-dimensional structuration leads to $2 \mathrm{D}$ colloidal crystals which are extensively employed in nanosphere lithography [24] (NSL), among others. NSL is based on the self-assembly of nanospheres into close-packed monolayers or bilayers, which are then employed as lithographic masks to fabricate nanoparticle arrays. Consequently, NSL is an efficient, inexpensive, inherently parallel, material-specific, and high-output process for nanostructure fabrication process which can systematically produce a $2 \mathrm{D}$ array of periodic structures.

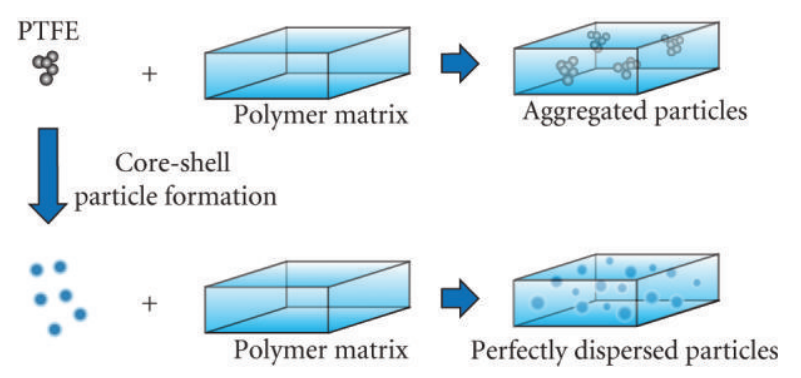

Scheme 1: PTFE dispersion improvement through the use of coreshell particles.

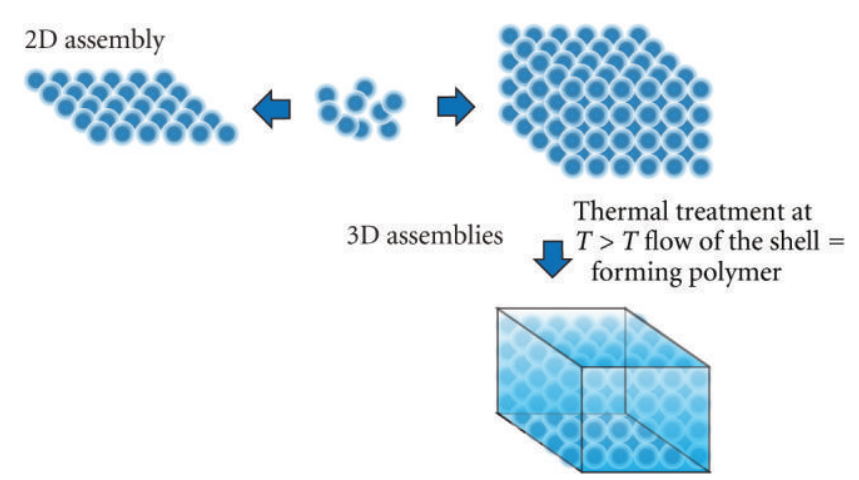

Scheme 2: 2D and 3D colloidal crystals from PTFE based core-shell particles.

The use of spherical colloids to obtain highly ordered periodic 3D structures, that is, photonic crystals, opens novel perspectives in organic photonics since the the periodic modulation in structure and composition allows to control light propagation and emission [25].

In addition to the building up of conventional opals, once a well-ordered assembly of core-shell particles is obtained, annealing at a temperature higher than the flow transition temperature of the shell-forming polymer allows the shellforming polymer to soften and form a matrix surrounding 3 D periodic array of in which the PTFE particles are arranged in regular registry. Since the characteristic size of the different domains is on the nanometer range, nanoscale thin films and three-dimensional materials can be prepared (Scheme 2).

For these applications, the particle size control represents the key to produce successful nanostructures. As monodispersed particles in the $30 \mathrm{~nm}$ to 1 micron size range are involved in the preparation of nanostructured materials, emulsion polymerization [26] is the most suitable particle forming technique. In this process, the most important parameter, that controls the particle nucleation, is the surfactant concentration. A narrow particle size distribution can be achieved when a low surfactant concentration is employed $[27,28]$. The "surfactant-free emulsion polymerization" (SFEP) represents an efficient technique to prepare monodisperse latexes because the time for nucleation is extremely short. However, SFEP approach affords particles with size generally comprised between 300 and $800 \mathrm{~nm}$ whose monodispersity is not always guaranteed. In addition, 
TABLE 1: PTFE latex characteristics.

\begin{tabular}{|c|c|c|c|c|c|c|}
\hline PTFE latex & Shape & $d(\mathrm{~nm})$ & Solid content $(\mathrm{g} / \mathrm{L})$ & No. of particles $\left(\mathrm{L}^{-1}\right)$ & Conductivity $(\mu \mathrm{S} / \mathrm{cm})$ & Zeta potential $(\mathrm{mV})$ \\
\hline BPM & Sphere & 20 & 150.8 & $1.7 \times 10^{19}$ & 850 & -56 \\
\hline BP44 & Sphere & 26 & 350.4 & $1.8 \times 10^{19}$ & 520 & -50 \\
\hline DV2 & Sphere & 33 & 358.3 & $6.8 \times 10^{18}$ & 460 & -38 \\
\hline $\mathrm{MD}$ & Sphere & 41 & 347.6 & $3.1 \times 10^{18}$ & 280 & -51 \\
\hline DV3 & Rod-like & 62 & 294.5 & $1.2 \times 10^{18}$ & 415 & -41 \\
\hline D60 & Sphere & 130 & 280.2 & $1.7 \times 10^{17}$ & 560 & -35 \\
\hline D60G & Sphere & 240 & 296.8 & $1.9 \times 10^{16}$ & 430 & -38 \\
\hline
\end{tabular}

a certain variability in the final average particle size is observed.

A related approach to prepare such nanosized particles $[29,30]$ relies on the seeded emulsion technique starting from seeds of a few nanometers. These can be prepared in situ by a self-seeding technique or can derive from a distinct preparation. Considering the latter approach, polytetrafluoroethylene (PTFE) latexes with particles in the submicrometer size range can be successfully employed as seeds in the emulsifier-free emulsion polymerization of various monomers including styrene [31,32], acrylic mixtures [33], or methyl methacrylate [34-36] or thus leading to a wide variety of core-shell nanosphere architectures featuring a relatively narrow size distribution. In this paper, we review our most recent results concerning preparation, properties and self-assembly behavior of PTFE-based coreshell particles using polytetrafluoroethylene (PTFE) latexes with particles in the submicrometer size range, as seeds in the emulsifier-free emulsion polymerization of various monomers thus leading to a wide variety of core-shell nanosphere architectures in which the shell-forming polymers can be designed with glass transition or flow transition temperatures above or below room temperature.

\section{Experimental Part}

2.1. Materials. The PTFE latexes employed in this study and provided by Solvay Solexis were marked BPM, BP44, DV2, DV3, D60, D60G, and MD. Their characteristics, including particle radius and particle shape, the solid content, the particle number concentration, and the conductivity are collected in Table 1. The monomers styrene (99\% Aldrich), butylacrylate ( $\geq 99 \%$, Aldrich), methylacrylate ( $\geq 99 \%$, Fluka), ethylacrylate ( $\geq 99 \%$, Fluka), and methyl methacrylate $(99 \%$ Fluka) were distilled under reduced pressure in nitrogen atmosphere and stored at $-18^{\circ} \mathrm{C}$ until use. Methacrylic acid ( $\geq 98.0 \%$, Fluka) and potassium persulfate $(98 \%$, Carlo Erba) were used without further purification. The $\mathrm{C} 1$ mixture is constituted by methylacrylate, ethylacrylate, and methacrilic acid with weight percent of 39,57 , and $4 \%$, respectively. The C2 mixture is constituted by butylacrylate and methacrilic acid with weight percent of 96 and 4\%, respectively.

2.2. General Preparation of PTFE-Based Core-Shell Nanospheres. The PTFE-based core-shell colloids were syn-
TABLE 2: Already published core-shell series and corresponding references.

\begin{tabular}{lc}
\hline Series & Reference \\
\hline MDS, DV2S, DV3S & {$[31]$} \\
BPMS & {$[32]$} \\
MDC1, MDC2 & {$[33]$} \\
MDM, DV2M, DV3M & {$[34]$} \\
BPM, D60M & {$[35]$} \\
MM & {$[36]$} \\
\hline
\end{tabular}

thesized in a $1 \mathrm{~L}$ five-neck jacketed reactor equipped with a condenser, a mechanical stirrer, a thermometer, and inlets for nitrogen and monomer(s). First, the appropriate amount of PTFE latex was introduced into the reactor containing $500 \mathrm{~mL}$ of deionized water at room temperature with a stirring rate of $300 \mathrm{rpm}$. The mixture was purged with nitrogen for $20 \mathrm{~min}$ and nitrogen was flushed during the entire polymerization procedure. Next, the mixture was heated to $75^{\circ} \mathrm{C}$ and the monomer(s) was added. Then, after additional $15 \mathrm{~min}$ of equilibration time, the potassium persulfate aqueous solution $(10 \mathrm{~mL}, 0.74 \mathrm{mmol})$ was added and the mixture was reacted for $24 \mathrm{~h}$. The obtained latex was purified from the unreacted monomer by repeated dialyses using a membrane with MWCO of $12.4 \mathrm{KDa}$. All the latexes were obtained following the above general procedure by varying the initial PTFE latex amount. Starting from the various PTFE seeds and changing the ratio between the PTFE and the monomer(s), several sample series were obtained. The series were marked with an acronym comprising the PTFE seed, the type of monomer or comonomeric mixture, and a number which relates to the initial PTFE weight percent with respect to the monomer or comonomeric mixture. As an example, the MDMn series is obtained from the MD latex and methylmethacrylate (M) whereas styrene and the two acrylic mixtures are indicated as $\mathrm{S}, \mathrm{Cl}$, and C2, respectively. The experimental details of the already published sample series are described in the corresponding papers as summarized in Table 2. The experimental details of series MDS and D60GS are reported in Tables 3 and 4.

2.3. Preparation of $2 \mathrm{D}$ and $3 \mathrm{D}$ Colloidal Crystals. 2D colloidal crystals were prepared by the floating technique [37-39], on the air liquid interface and then lifted on the surface of a solid substrate. With this method, the original dispersion 
TABLE 3: Synthesis details, yield, and solid content of the various samples.

\begin{tabular}{|c|c|c|c|c|c|}
\hline Sample & Volume of water (mL) & Volume of Styrene (mL) & Volume of PTFE latex (mL) & Yield (\%) & Solid content $(\mathrm{g} / \mathrm{mL})$ \\
\hline MDS1 & 500.0 & 70.0 & 0.46 & 89.6 & 0.1078 \\
\hline MDS2 & 500.0 & 70.0 & 0.92 & 98.4 & 0.1104 \\
\hline MDS3 & 500.0 & 70.0 & 1.85 & 100.0 & 0.1140 \\
\hline MDS4 & 500.0 & 70.0 & 5.67 & 100.0 & 0.1210 \\
\hline MDS5* & 500.0 & 70.0 & 10.00 & 76.4 & 0.1121 \\
\hline MDS6 & 500.0 & 70.0 & 18.10 & 100.0 & 0.1241 \\
\hline MDS7* & 500.0 & 70.0 & 19.90 & 77.0 & 0.1128 \\
\hline MDS8* & 500.0 & 70.0 & 39.90 & 83.0 & 0.0650 \\
\hline MDS9* & 500.0 & 70.0 & 59.40 & 81.7 & 0.1247 \\
\hline D60GS1 & 500.0 & 70.0 & 30.65 & 85.3 & 0.1106 \\
\hline D60GS2 & 500.0 & 70.0 & 50.30 & 83.6 & 0.1087 \\
\hline
\end{tabular}

${ }^{*}$ Published in [31].

TABle 4: Sample composition derived from TGA and DSC, glass transition temperature, diameter estimated, PCS Size, SEM size, and uniformity ratio of the various samples.

\begin{tabular}{|c|c|c|c|c|c|c|c|}
\hline Sample & \% PTFE Theorical (W/W) & \% PTFE (TGA) & \% PTFE (DSC) & $d$ estimated $(\mathrm{nm})$ & $d$ PCS $(\mathrm{nm})$ & $d \operatorname{SEM}(\mathrm{nm})$ & Uniformity Ratio $U$ \\
\hline MDS1 & 0.25 & 0.21 & 0.11 & 383 & 417 & 380 & 1.003 \\
\hline MDS2 & 0.50 & 0.47 & 0.33 & 304 & 309 & 301 & 1.004 \\
\hline MDS3 & 1.00 & 0.85 & 0.67 & 241 & 245 & 237 & 1.005 \\
\hline MDS4 & 3.00 & 2.91 & 2.08 & 167 & 166 & 163 & 1.007 \\
\hline MDS5* & 5.20 & 5.20 & 4.30 & 138 & 139 & 133 & 1.012 \\
\hline MDS6 & 9.00 & 8.70 & 7.67 & 114 & 115 & 111 & 1.028 \\
\hline MDS7* & 9.80 & 6.70 & 7.9 & 111 & 113 & 107 & 1.030 \\
\hline MDS8* & 17.90 & 19.4 & 16.8 & 89 & 92 & 84 & 1.050 \\
\hline MDS9* & 24.50 & 22.7 & 22.7 & 80 & 89 & 75 & 1.100 \\
\hline D60GS1 & 12.5 & 12.0 & 12.4 & 596 & 604 & 593 & 1.004 \\
\hline D60GS2 & 19.0 & 18.0 & 19.3 & 511 & 525 & 500 & 1.004 \\
\hline
\end{tabular}

* Published in [31].

(eventually diluted to reach typical concentrations ranging from 5 to $10 \%$ in water) is mixed with ethanol $(1: 1 \mathrm{~V} / \mathrm{V})$. This gives an accurate control of the floating level of the monolayers on the water surface thus allowing the formation of large 2D crystals screening the surface charge on the sphere by water molecules. The final addition of a surfactant in the water further compacts the $2 \mathrm{D}$ crystalline islands. In this phase, parameters like sphere surface charge, ethanol content, and dispersion method are rather critical in the formation of large crystal assemblies. Silicon substrates have been used to lift the floating crystals.

$3 \mathrm{D}$ colloidal crystals were grown by using the vertical deposition technique [40] starting from core-shell latexes properly diluted with deionized water. Growth occurred on glass substrates at $45 \pm 1^{\circ} \mathrm{C}$ inside a BF53 Binder incubator. Opals were composed of flat domains with the [111] direction of the face-centered cubic lattice of spheres perpendicular to the substrate. In the best samples, domain sizes are 50-100 microns. However, defects inside these domains, in particular stacking faults, cannot be excluded. Opals are marked with the prefix $\mathrm{O}$ before the name of the sample employed to build up the corresponding opal.
2.4. Characterization. Scanning electron microscope (SEM) analysis was performed using an Inspect F SEM-FEG (Field Emission Gun) from FEI company, with a beam diameter of $3 \mathrm{~nm}$. The SEM micrographs were elaborated by the Scion Image processing program. Photon correlation spectroscopy (PCS) analysis at $25^{\circ} \mathrm{C}$ was performed with a Malvern Zetasizer $3000 \mathrm{HS}$ at a fixed scattering angle of $90^{\circ}$, using a $10 \mathrm{mV}$ He-Ne laser and PCS software for Windows (version 1.34, Malvern, UK). Each value is the average of five measurements. The instrument was checked with a standard polystyrene latex with a diameter of $200 \mathrm{~nm}$. Electrophoretic mobility was measured with a Malvern Zetasizer 3000 HS. Each value is the average of five measurements.

SFM analysis was performed with Tapping-Mode Atomic Force Microscopy in air on a Multimode Nanoscope IIIa instrument (Veeco, S. Barbara, CA, USA) operated in constant amplitude mode. A multilayer of nanoparticle is obtained by drop casting and aliquot of water suspension on a disc of freshly cleaved muscovite mica (Electron Microscopy Sciences, Hatfield, PA, USA) and the solvent is allowed to slowly evaporate. Images are then subjected to flattening using the microscope constructor software. 


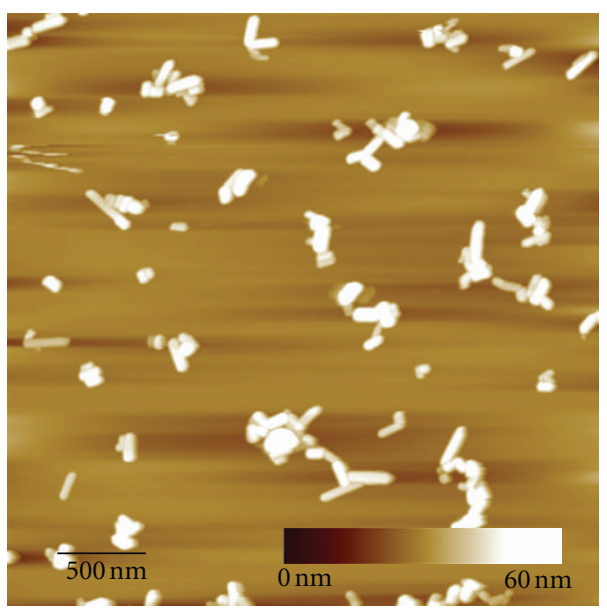

(a)

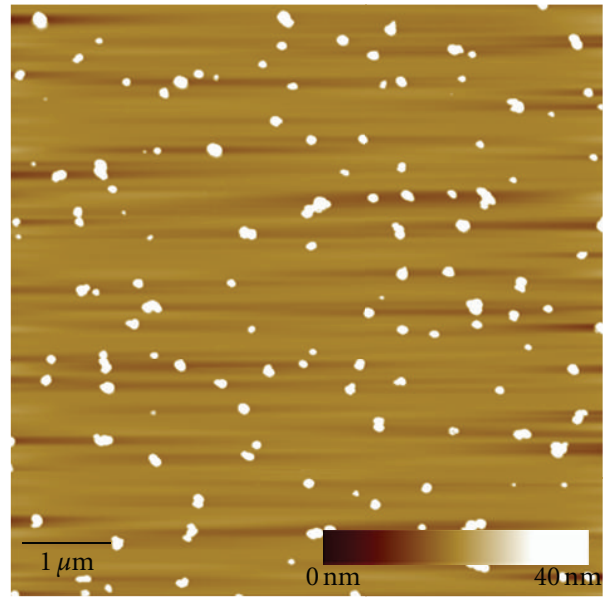

(b)

Figure 1: AFM images of sample DV3 (a) and MD particles (b) [34].

Thermogravimetric analysis (TGA) was performed with a Mettler-Toledo TGA/SDTA851 $1^{\mathrm{e}}$ at a scanning rate of $10^{\circ} \mathrm{C} / \mathrm{min}$ from room temperature up to $1100^{\circ} \mathrm{C}$ under nitrogen flow. The solid content of latex dispersions was determined by TGA. Differential scanning calorimetry (DSC) was carried out using a Mettler-Toledo DSC 821 apparatus. Samples of about $5 \mathrm{mg}$ were employed. The instrument was calibrated with high purity standards at $10^{\circ} \mathrm{C} \cdot \mathrm{min}^{-1}$. Dry nitrogen was used as purge gas.

Reactive Ion Etching (RIE) was performed in oxygen plasma, at an operative pressure of 3.0E-1 mbar, flux of 80 $\mathrm{sccm}, 80 \mathrm{~W}$ RF power, with etching time ranging from 20 to 120 seconds.

Transmittance $(T)$ and reflectance $(R)$ spectra were recorded with Avantes Avaspec-2048 compact spectrometers (230-1100 nm spectral range, $\sim 1.4 \mathrm{~nm}$ spectral resolution). Light from a combined deuterium/tungsten-halogen lamp was guided by an optical fiber to a proper collimating optics (spot diameter variable in the range $0.5-5 \mathrm{~mm}$ ) on the sample, which is mounted on a goniometer. Transmitted light was collected and driven by another optical fibers to the spectrometer. Normal incidence reflectance was measured on six different $2 \mathrm{~mm}$ diameter spots by a Y reflection probe bundle fiber. Light was linearly polarized by using a GlennThompson Halbo Optics polarizer. All details on the optical set-up are reported in [41].

\section{Results and Discussion}

3.1. Synthesis. PTFE latexes with different size and shape were prepared by microemulsion polymerization and employed as seeds in the successive emulsifier-free seeded emulsion polymerizations. In particular, BPM, BP44, DV2, $\mathrm{MD}, \mathrm{D} 60$, and D60G latexes consist of spherical particles with average diameters of 20,26,33,41, 130, and $240 \mathrm{~nm}$ whereas DV3 consists of rod-like particles with an equivalent radius of $62 \mathrm{~nm}$ and an axial ratio of 3.2 (Table 1). As typical examples, Figure 1 reports the AFM images of samples MD and DV3. As the presence of the residual surfactant deriving from the TFE microemulsion polymerization could interfere with the successive emulsifier-free seeded emulsion polymerization, all the PTFE latexes were thoroughly dialyzed. At the end of the purification process, the conductivity of all the PTFE latexes was lower than $150 \mu \mathrm{S} / \mathrm{cm}$.

The emulsifier-free seeded emulsion polymerizations of the various monomers including styrene, methylmethacrylate, and the acrylic mixtures $\mathrm{C} 1$ and $\mathrm{C} 2$ were performed by adding appropriate amounts of the PTFE latex and monomers into deionized water and running the reactions at $75^{\circ} \mathrm{C}$ for $24 \mathrm{hrs}$ using potassium persulfate as the free radical source. At the end of the reaction, the latexes were purified by repeated dialyses. In all the polymerization reactions, monomer(s) and potassium persulfate as well as the water content were kept constant, whereas variations were allowed in the amount of PTFE. Under these conditions, the initial PTFE weight percent with respect to monomer(s), and PTFE was varied from 0.25 to $90 \%$. No gel trace or polymeric gross aggregates were found in all cases. Nearly quantitative monomer conversion and nanosphere yield were obtained. The final latexes are very stable (up to two years).

\subsection{Size and Size Distribution of the Core-Shell Particles.} Figure 2 reports the SEM micrographs of samples D60GS1, MDS3, BPM7, and DV2M1.

Although these samples are prepared starting from PTFE seeds differing in their size and using styrene or methylmethacrylate as the shell-forming monomer(s), in all cases they feature a quite narrow size distribution.

The composition of all the samples can be easily estimated from the TGA analysis, as reported in Figure 3 for typical samples. In all the thermograms, there are two main losses. The lower temperature loss is associated to the degradation of the shell-forming polymers which occurs at $410^{\circ} \mathrm{C}$ (midpoint) for polystyrene, at $350^{\circ} \mathrm{C}$ for polymethylmethacrylate, and at $390^{\circ} \mathrm{C}$ for the two acrylic mixtures $\mathrm{C} 1$ and $\mathrm{C} 2$ whereas the weight loss at $570^{\circ} \mathrm{C}$ 


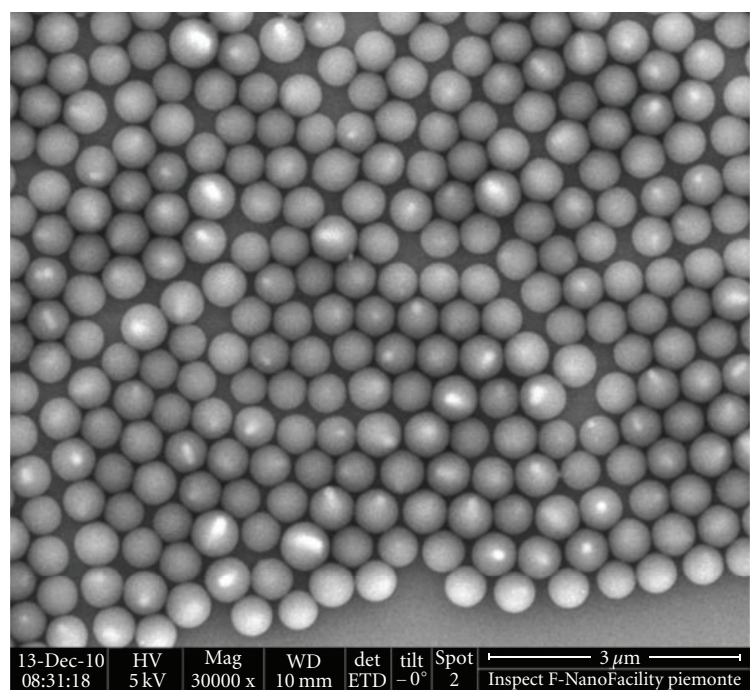

(a)

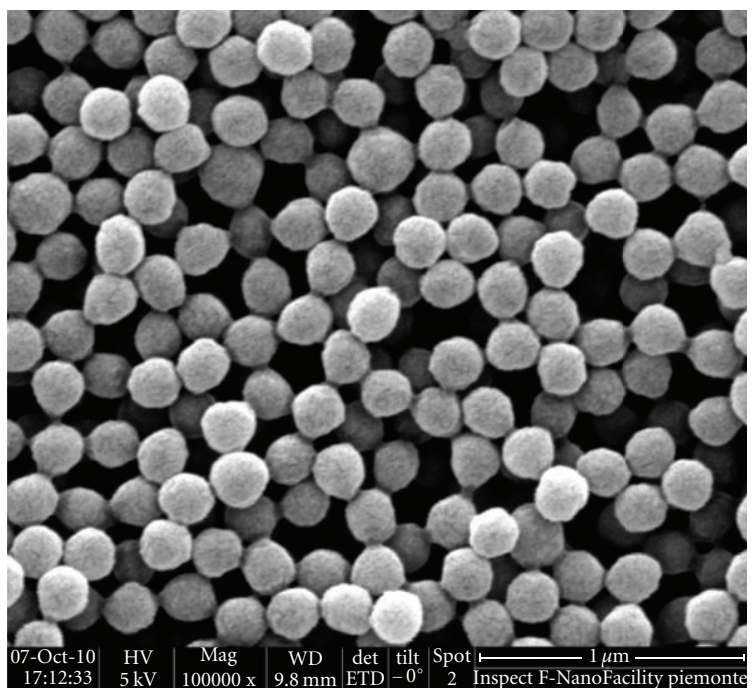

(c)

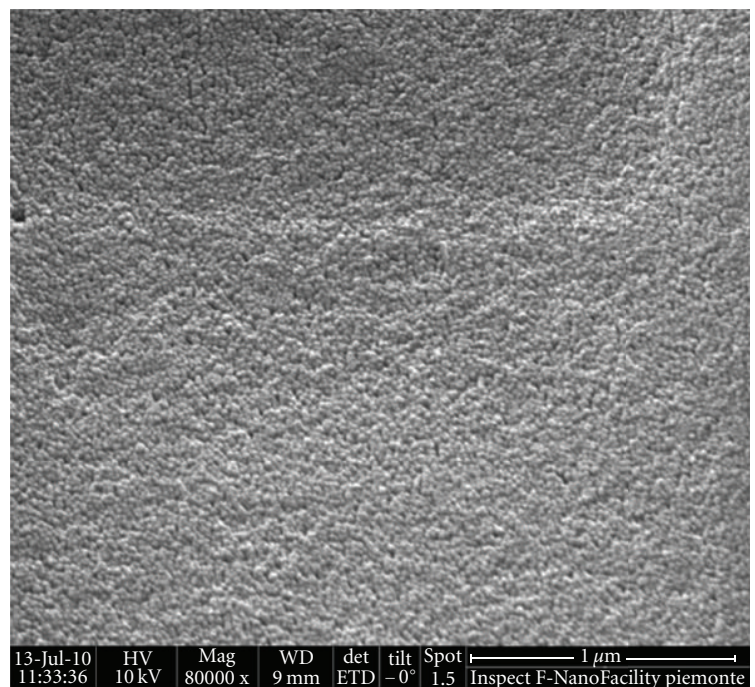

(b)

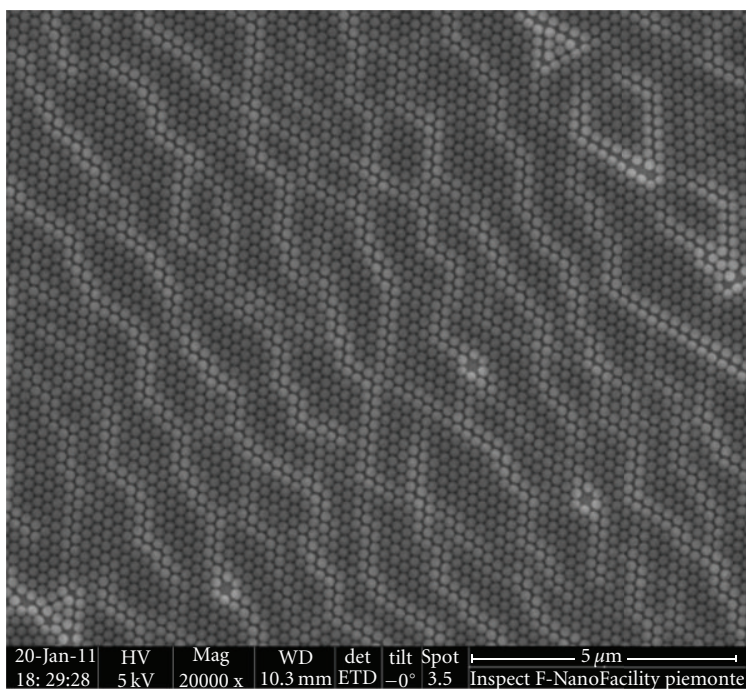

(d)

Figure 2: SEM micrographs of samples D60GS1 (a), BPM7 (b), DV2M1 (c), and MDS3 (d) [34, 35].

corresponds to PTFE decomposition. The composition of the various samples is in excellent agreement with the one calculated from the amount of the initially added PTFE and monomer or comonomeric mixtures.

The size and size distribution of the various samples were studied using a combination of SEM, AFM, and PCS analysis. Figure 4 reports typical PCS curves for MDSn series and, for comparison purposes, the PCS curve of the MD latex. No residual PTFE deriving from MD latex is present in the various samples, thus indicating that PTFE is highly efficient as seed in the styrene polymerization.

Figure 5 reports the SEM images for series MDSn as well as the size distribution, including the uniformity ratios $U$ [42] whereas Figure 6 illustrates the trend of the particle diameter and the uniformity ratio as a function of the S/PTFE weight ratio.
Over the entire S/PTFE range, the particle size increases as the S/PTFE ratio increases indicating that secondary nucleation was prevented with all the monomer ending up as shell polymer. In addition, the uniformity ratio $U$ decreases regularly as the ratio S/PTFE increases.

The described trend is observed in all the sample series prepared starting from the various PTFE seeds and using styrene or methylmethacrylate. To make a homogeneous comparison, the size and $U$ data are plotted as a function of the ratio between the amount of styrene or methylmethacrylate and the number of PTFE particles in the reaction mixture. Figure 7 illustrates the various data.

For both monomers, the size and uniformity ratio trends are very similar. The particle size increases as the ratio between the amount of monomer and the number of PTFE particles increases whereas the relevant size distribution 


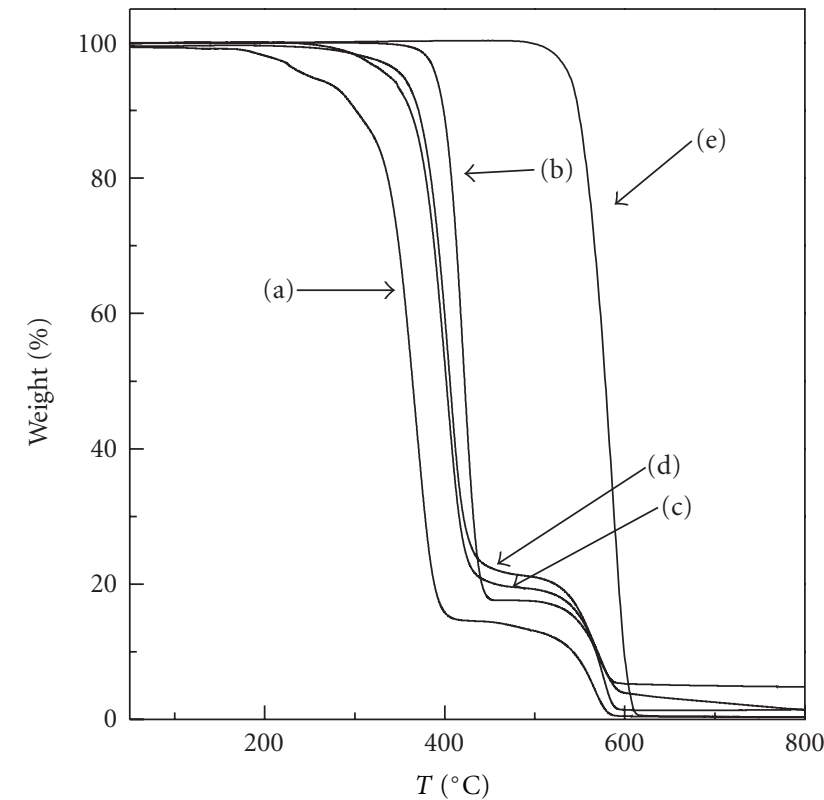

Figure 3: TGA curves at $10^{\circ} \mathrm{C} / \mathrm{min}$ heating for various samples: DV2M4 (a), D60GS2 (b), 18MDC1 (c), 18MDC2 (d), and latex MD (e) $[33-35]$.

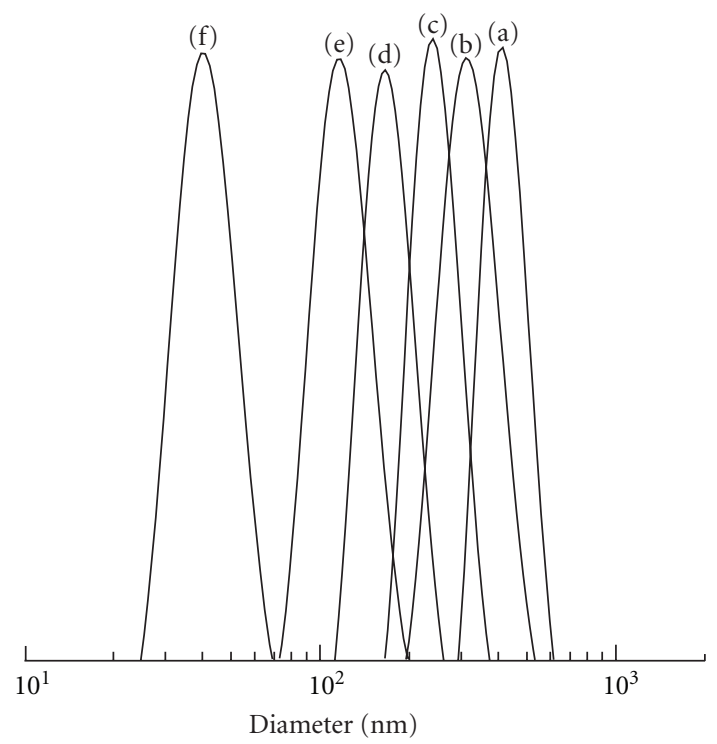

FIGURE 4: PCS spectra of MDS1 (a), MDS2 (b), MDS3 (c), MDS4 (d), MDS6 (e), and latex MD (f), (unpublished data).

decreases. Provided that no pure PMMA and PS or PTFE nanospheres are present at the end of the reaction, and taking into account the yield values, the size of the coreshell nanospheres can be estimated from the amount of the initially added PTFE and the relevant monomer. In all cases, the estimated size is in close agreement with the observed one. This indicates that over the entire monomer/PTFE range, secondary nucleation was prevented with all the monomer ending up as shell polymer. The inhibition of the secondary nucleation suggests that the PTFE seed particles are able to capture all the unstable nuclei produced in the system even at very high monomer/PTFE ratios, thus avoiding the formation of stable secondary particles. A direct consequence of this observation is that particle size versus S/PTFE curve is superposable to the particle size versus M/PTFE curve. The overall picture of these data clearly indicates that a very precise control over the particle size and size distribution can be exerted by properly adjusting the ratio between the monomer and the PTFE seed.

It is also interesting to speculate about the tendency toward an increasing size uniformity as the ratio monomer/seed increases. During Smith-Ewart Interval II [19], the growing mechanism involves diffusion of monomer from the droplets to the particles and the growing probability appears related to the latex particle surface area. Consequently, bigger particles should display a growing probability higher than smaller particles. However, this mechanism would ultimately lead to an increase in the size distribution, in contrast with the experimental observations. We suggest that the thermodynamic tendency toward a reduction of the surface to volume ratio could produce an increased tendency of the smaller particles to absorb the monomer with respect to the bigger ones thus ultimately leading to size uniformity, provided that the monomer to seed ratio is sufficiently high. This suggestion is also in agreement with the competitive growth mechanism [19] of latex particles which indicates that small latex particles grow faster in size than larger ones, thus leading to narrow size distribution, when the particle size is lower than the critical value of $150 \mathrm{~nm}$ whereas the opposite occurs when the particle size is much larger than $150 \mathrm{~nm}$. This general behavior is also very similar to the one described [43] for the seeded dispersion polymerization of methylmethacrylate using PMMA submicron seeds. In that system, the final number of particles was nearly the same as the initial number of seed particles thus allowing the final particle size to be precisely controlled leading to the target particle size with excellent reproducibility. In addition, although no explanation was given, a self-sharpening of the size distribution was also observed with increasing the monomer to seed ratio.

Similar results can be obtained in the case of the seeded polymerization of the two acrylic mixtures $\mathrm{C} 1$ and $\mathrm{C} 2$ starting from the MD PTFE seed. As a typical example, Figure 8 reports the AFM image of sample MDC1-3.

No residual MD latex is present in the various samples and monomodal and narrow size distribution of the latex particles are generally obtained. However, the particle size estimated assuming the presence of core-shell nanospheres only and quantitative yield is definitely lower than the coreshell particle diameters observed for series MDC1n and MDC2n (Figure 9).

In addition, the size of samples belonging to MDC1n series is always higher than the one of the corresponding samples of MDC2n series. These two observations suggest that in both sample series the shell is swollen in water possibly due to the presence of the ionic and $\mathrm{pH}$-sensitive methacrylic acid units. The swelling degree appears lower for series nMDC2 due to the presence of butylacrylate units 


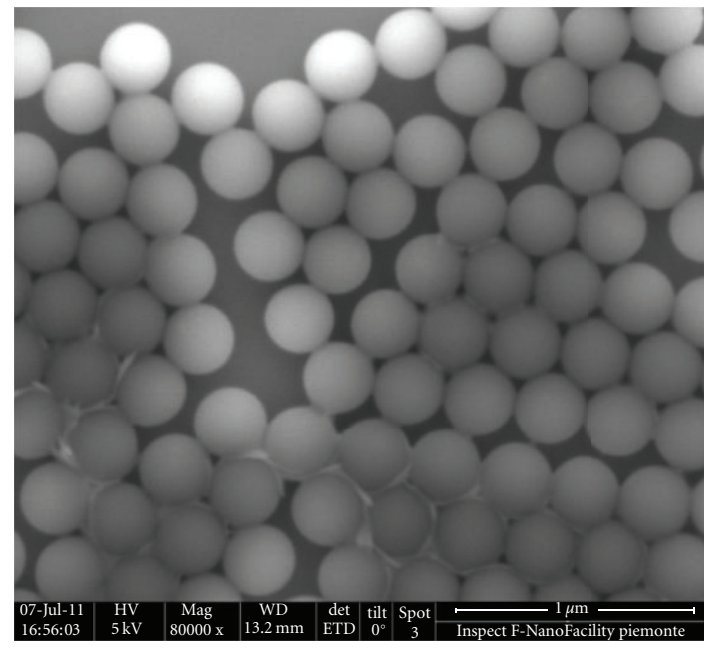

(a)

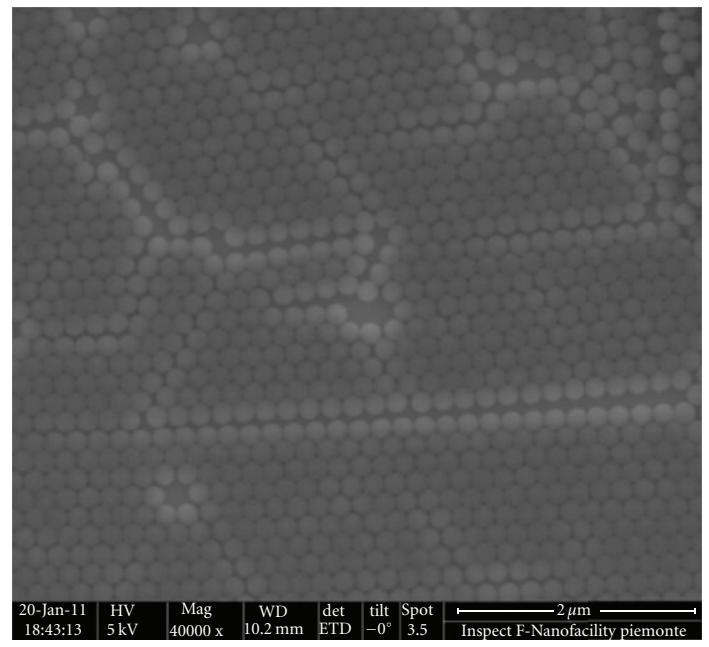

(c)

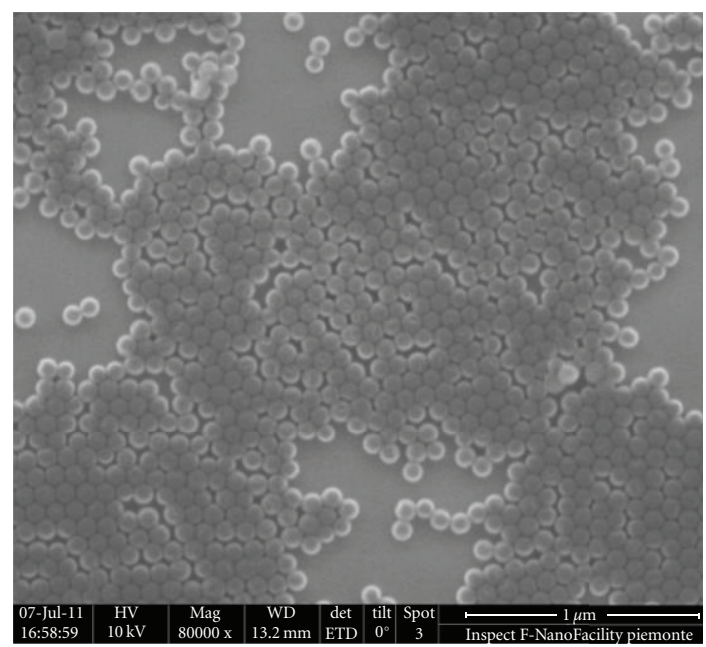

(e)

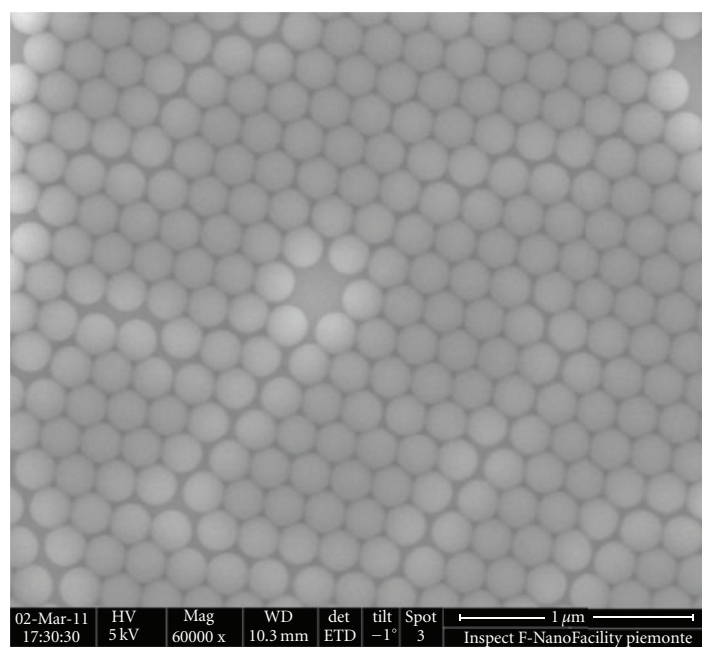

(b)

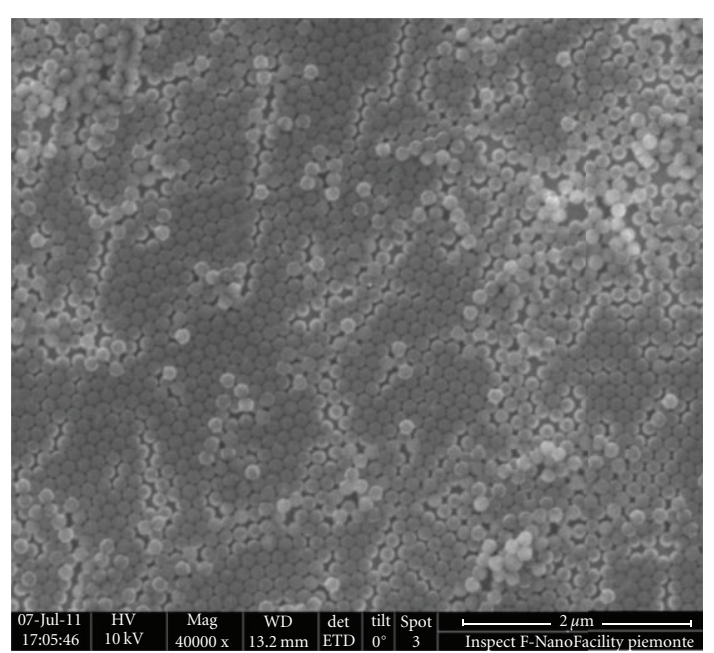

(d)

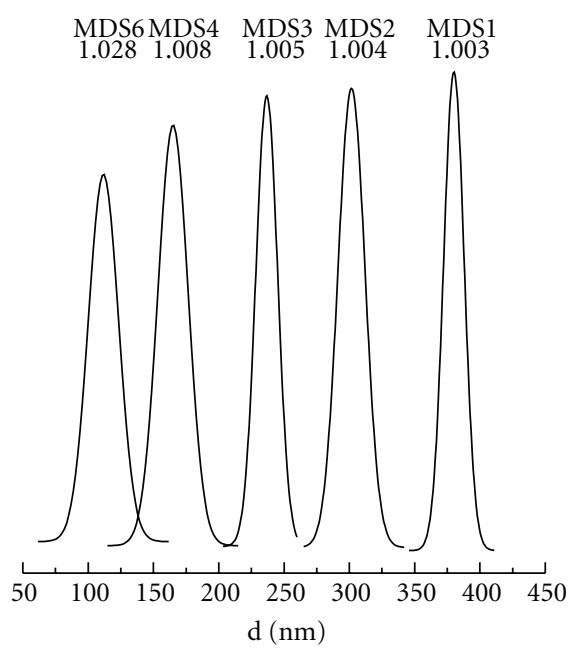

(f)

FIgURE 5: SEM micrograph of samples MDS1 (a), MDS2 (b), MDS3 (c), MDS4 (d), MDS6 (e), and relative diameter distribution (f), (unpublished data). 


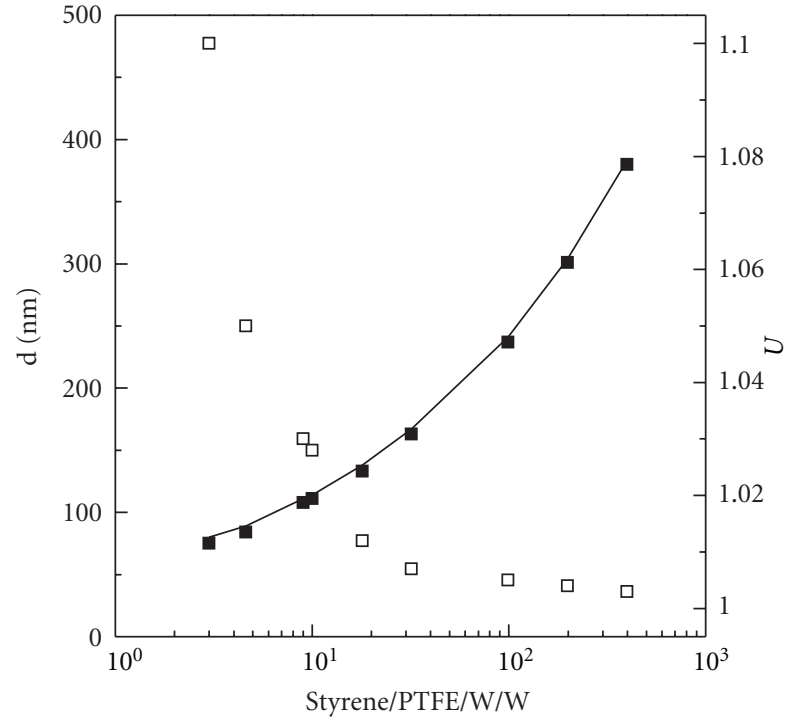

FIgURE 6: Particle size $(d)$ and uniformity ratio $(U)$ as a function of the S/PTFE weight ratio [31].

which are less hydrophilic than methyl- or ethylacrylate units which constitute the shell of nMDC1 series. PCS measurements confirmed this hypothesis and indicated a $\mathrm{pH}$ dependence of the particle size. This effect could be employed to produce $2 \mathrm{D}$ ordered layers with distinct periodicities by assembling the core-shell particles after equilibration at different $\mathrm{pH}$ values.

3.3. Thermal Behavior. The thermal behavior of the various samples was studied by combined differential scanning calorimetry and thermogravimetric analysis. Figure 10 illustrates the DSC heating and cooling traces of various sample in which the shell is constituted by PMMA, C1, and PS. The same figure reports the DSC traces of the seed MD, as a typical PTFE sample. In all the core-shell samples, at low temperature a step can be observed, due to the glass transition of the shell-forming polymer whereas, at high temperature, an endothermic transition is present, attributed to the PTFE melting. The crystallization of MD sample, at $-10^{\circ} \mathrm{C} / \mathrm{min}$ cooling rate, is observed at $310^{\circ} \mathrm{C}$ in agreement with literature data [44]. In contrast, the crystallization of PTFE cores in the three core shell samples occurs at $270^{\circ} \mathrm{C}$. This peculiar crystallization behavior, recently described and thoroughly discussed [45] for a series of PTFE/PMMA coreshell nanoparticles, and also observed in PTFE blends with polyamides $[12,13]$, can be rationalized within the frame of the fractionated crystallization mechanism [46]. It is a characteristic of crystalline polymers to exhibit multiple crystallization transitions when dispersed as small particles [46] as may occur in some polymer blends $[47,48]$ or microphase separated in block copolymers [49]. In these cases, the number of the dispersed particles is much greater than the number of heterogeneities that usually nucleate the polymer in bulk. Then, the polymer crystallization occurs in one or more stages reflecting the nucleation

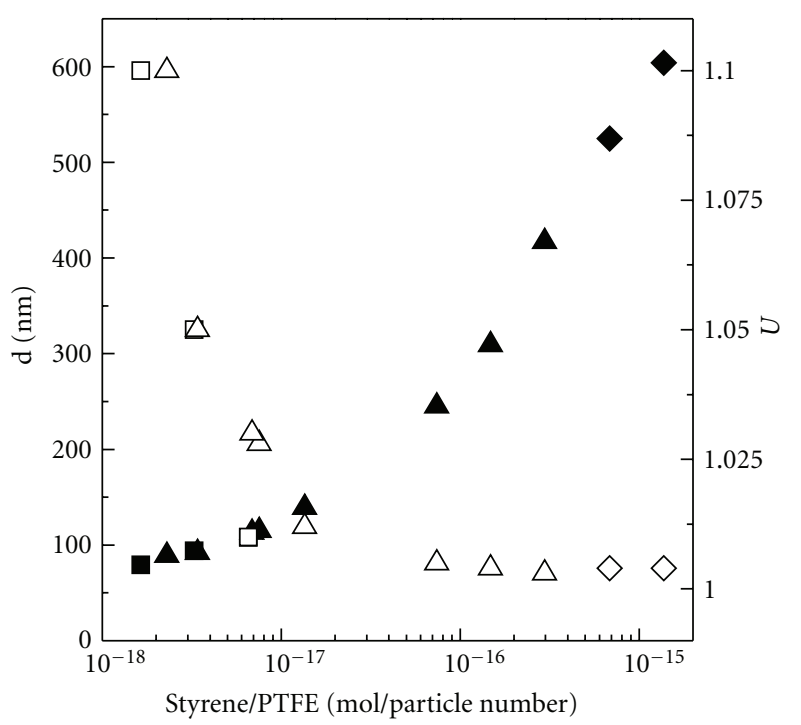

(a)

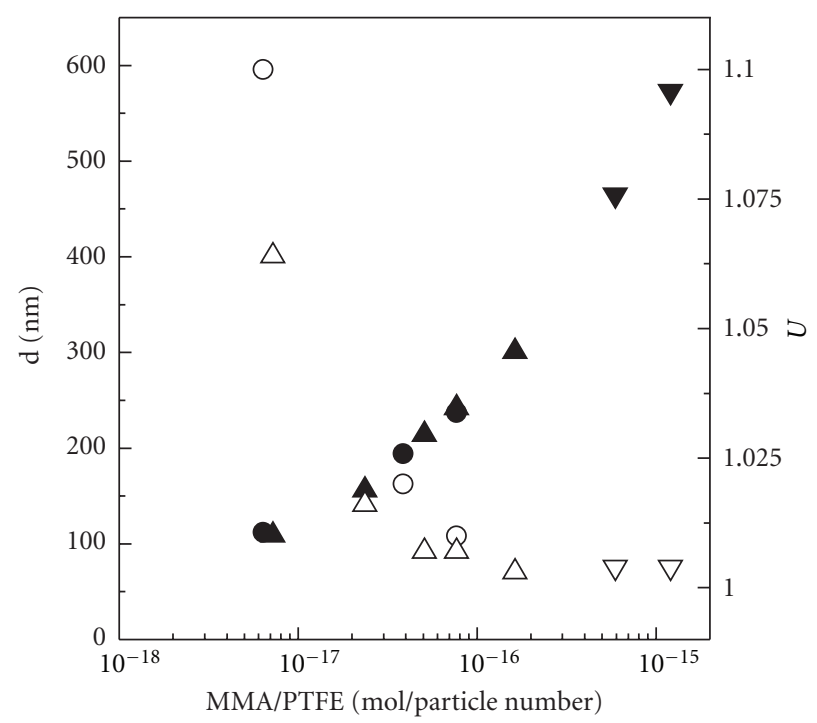

(b)

Figure 7: Particle size ( $d$, fully symbols) and uniformity ratio ( $U$, open symbols) as a function of the initial mol of monomer/PTFE particle number ratio for styrene (a) and methylmethacrylate (b): $\operatorname{BPM}(\boldsymbol{\square}), \operatorname{BP} 44(\bullet), \mathrm{MD}(\boldsymbol{\Delta}), \mathrm{D} 60(\boldsymbol{\nabla})$, and D60G $(\bullet),[31,32,34-$ 36].

by different heterogeneities and consequently activated at different degrees of undercooling. The particles that do not contain a heterogeneity eventually nucleate through homogeneous nucleation, at the largest undercooling. In the present case, due to the compartmentalization of PTFE within the core-shell nanospheres, the number of the dispersed PTFE particles is much greater than the number of heterogeneities that usually nucleate the polymer in bulk. In these conditions, only one crystallization component at very high undercooling is observed, possibly deriving from the homogeneous nucleation mechanism. In turn, the observation of the single low-temperature crystallization 


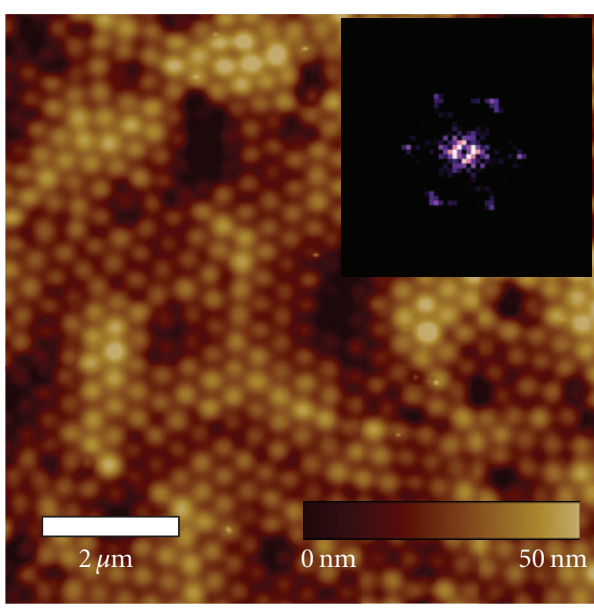

Figure 8: AFM image and 2D Fourier spectrum (inset) for the MDC1-3 specimen. Tapping-mode AFM image obtained from a film of core-shell nanoparticles that has been obtained from solvent evaporation on a drop-casted spread on a freshly cleaved muscovite mica disc. Heights are coded in shades according to the reported colour bar. The 2D Fourier transform of the central portion of the image (in the inset) shows the six intensity peaks denoting periodicity and hexagonal compact structure of the film with a periodicity of approximately $300 \mathrm{~nm}$ (correspondent to the measured average interparticle distance) [33].

exotherm can be viewed as a proof for the occurrence of a perfect dispersion of the PTFE seeds.

It should be observed that the melting of PTFE occurs at a temperature at which the shell forming polymers undergo thermal degradation. In fact, Figure 11 reports a series of successive DSC heating and cooling curves for sample. In the first cooling curve only the crystallization at $270^{\circ} \mathrm{C}$ can be observed whereas in the successive cooling traces the PTFE crystallization is structured into two components but it is apparent that the relative intensities of the peaks is different from the previous cooling curve. In particular, the intensity of the crystallization peak at $310^{\circ} \mathrm{C}$ increases whereas the opposite occurs for the crystallization component at $270^{\circ} \mathrm{C}$.

This phenomenology is related to the parallel thermal decomposition of the PMMA shell which occurs through the well-known mechanism of random chain scission and followed by depropagation [50-52]. The unzipping and loss of the MMA allow the PTFE seeds to coalesce (Scheme 3).

The resulting increase in the PTFE domain size increases in turn the crystallization propensity of PTFE as demonstrated by the appearance and progressive growth of the PTFE crystallization component at $310^{\circ} \mathrm{C}$.

3.4. $2 D$ and $3 D$ Colloidal Crystals. Several experiments were performed to obtain ordered 2D and 3D colloidal crystals. In particular, $2 \mathrm{D}$ colloidal crystal of spheres was formed by the floating technique [37-39], on the air liquid interface and then lifted on the surface of a solid substrate. Ordered monolayer samples of BPMS-3 underwent Reactive Ion Etching (RIE), a physical-chemical dry etching technique widely used in silicon technology to remove material in

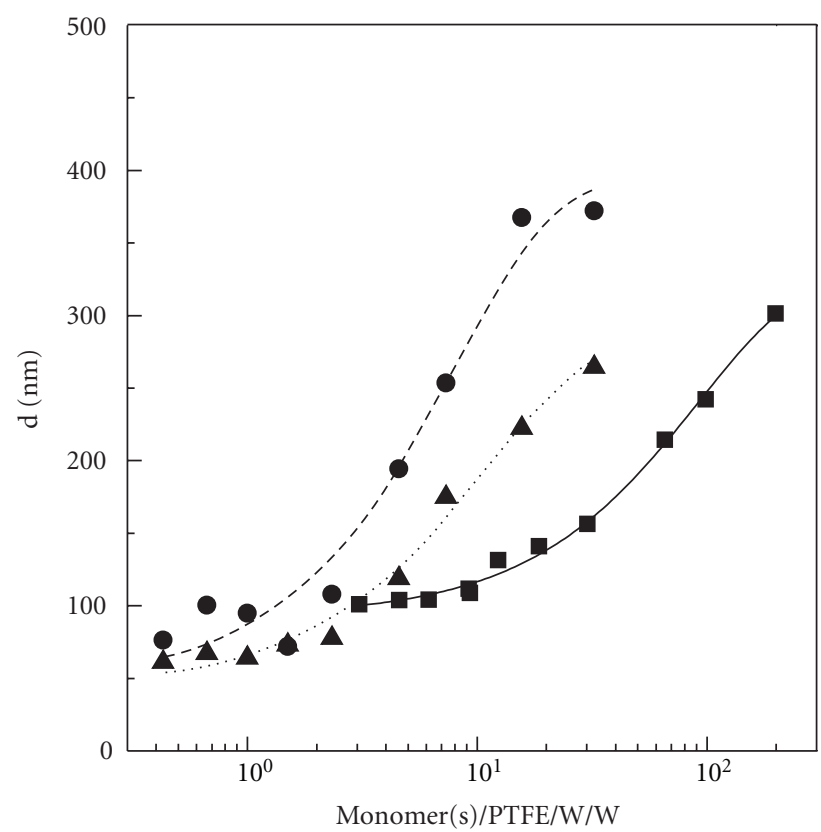

FIGURE 9: Trend of particle diameter as a function of initially PTFE added using MD latex as seed and different acrylic mixtures for shell: methyl methacrylate ( $\square$ and continuous line), acrylic mixture C1 ( $\bullet$ and dashed line), and acrylic mixture C2 ( $\boldsymbol{\Delta}$ and dotted line) $[33,34,36]$.

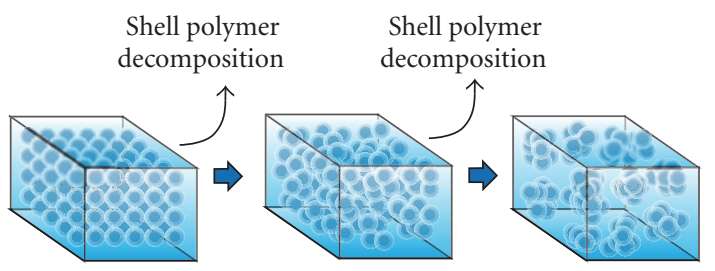

Scheme 3: Decomposition of PMMA and PTFE seeds coalesce for a sample subjected to DSC heating-cooling cycles.

excess during microfabrication processes. The RIE was performed in oxygen plasma, at an operative pressure of 3.0E-1 mbar, flux of $80 \mathrm{sccm}, 80 \mathrm{~W}$ RF power, at different etching time ranging from 20 to 120 seconds, as illustrated for a typical preparation in Figure 12.

Once subjected to RIE treatment, the nanospheres start reducing in size but the $2 \mathrm{D}$ structuring is not lost possibly because of the ionic anchoring of the negatively charged particles to the silicon surface. As the RIE time increases, the particle size decreases but the $2 \mathrm{D}$ ordering does not appear substantially perturbed. As the final particle size after $80 \mathrm{~s}$ RIE time is about $35 \mathrm{~nm}$. This value represents the smallest 2D nanostructuration obtained by RIE [53] for the preparation of masks with a combination of nanosphere lithography and reactive ion etching.

$3 \mathrm{D}$ colloidal crystals were prepared starting from various MDMn latexes. The corresponding opals, named OMDMn, were composed of flat domains with the [111] direction of the face-centered cubic lattice of spheres perpendicular to the glass substrate. The evolution of the stop band 


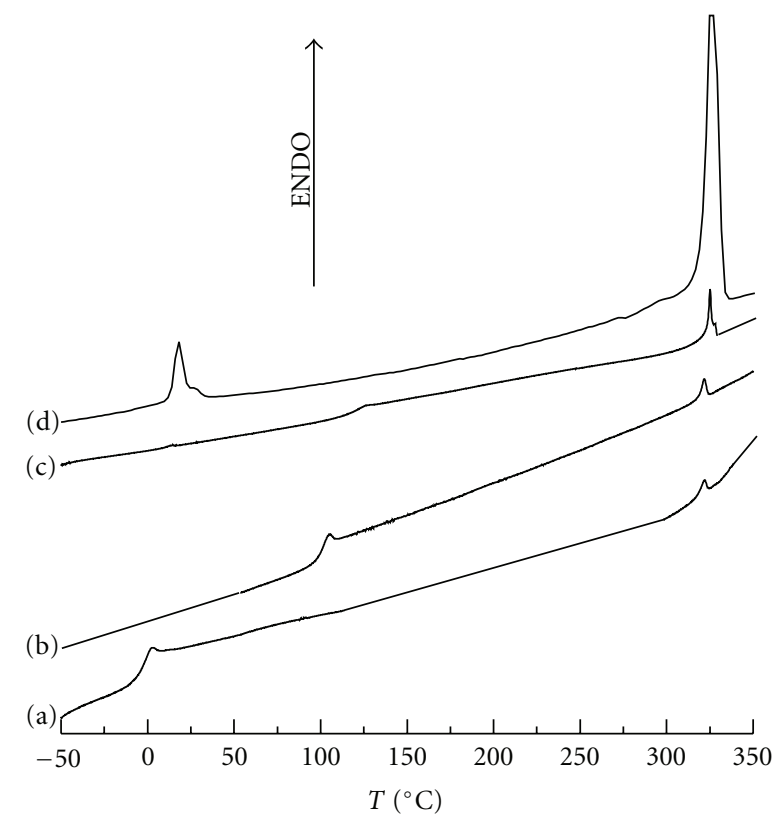

(A)

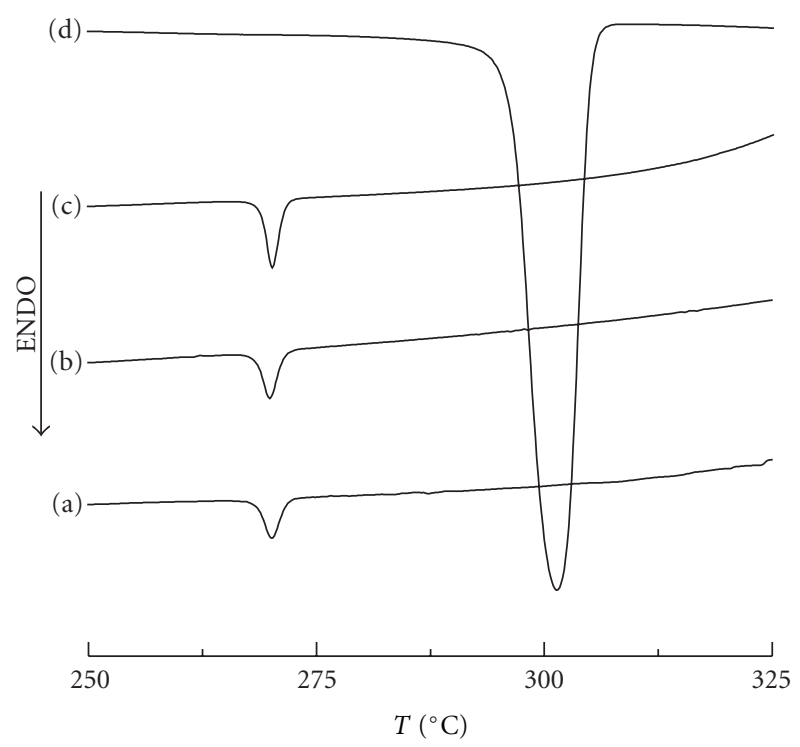

(B)

Figure 10: DSC first heating (A) and first cooling (B) at $10^{\circ} \mathrm{C} / \mathrm{min}$ of samples MDC1-3 (a), MDS3 (b), MM4 (c), and latex PTFE (d). DSC traces for PTFE sample were divided by ten times [31-33, 36].

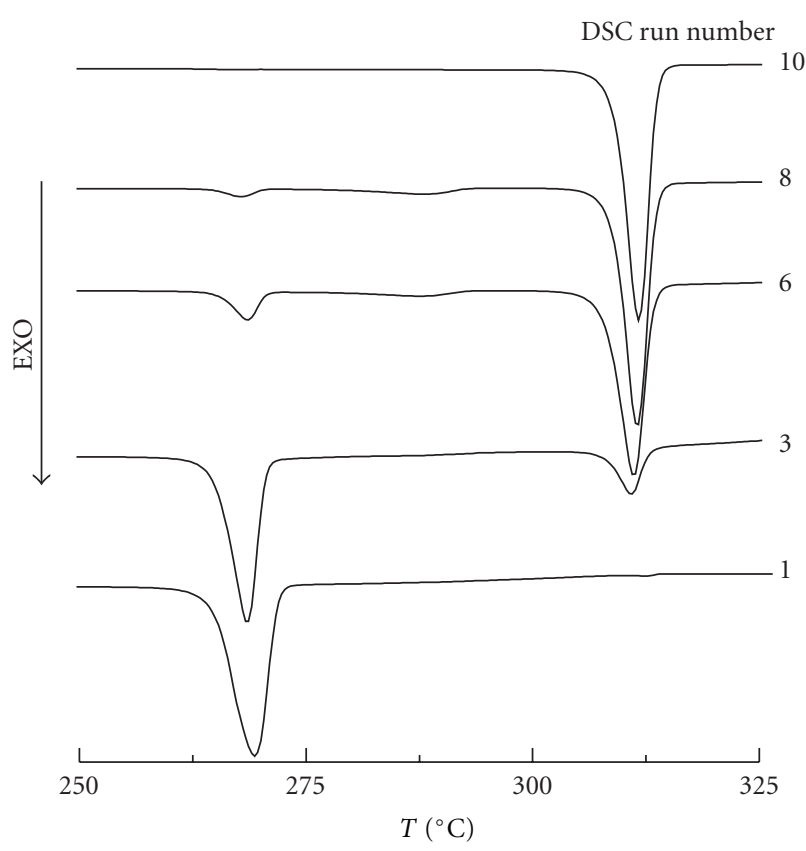

Figure 11: Successive DSC cooling curves at $10^{\circ} \mathrm{C} / \mathrm{min}$ of DV2M4 sample subjected to a series of heating-cooling cycles from 200 to $360^{\circ} \mathrm{C}$ [45].

was studied both by reflectance spectra and transmittance spectroscopy at varying angles of incidence and as a function of polarization.
Figure 13 shows the SEM image of the opal OMDM1 and the corresponding near normal incidence reflectance spectrum.

The main reflectance peak is assigned to the Bragg peak due to the pseudogap along the TL (111) crystallographic direction of the FCC colloidal crystal. The spectral position of the stop band is determined only by the lattice spacing and the refractive index of composing materials [54]. A simple analytical form for the Bragg peak position, widely adopted for opals, is provided by the Bragg-Snell law [55]:

$$
m \lambda_{B}=2 D \sqrt{n_{\mathrm{eff}}^{2}-\sin ^{2} \theta},
$$

where $m$ is the diffraction order, $D$, the interplanar spacing; $n_{\text {eff }}$, the effective refractive index of the $\mathrm{PhC}$, and $\theta$ the incidence angle. In the case of a close packed FCC lattice, $D=(2 / 3)^{0.5} d$.

Additional features are observed in the reflectance spectrum below $400 \mathrm{~nm}$. These peaks are a consequence of the complex opal photonic band structure occurring at energies higher than the pseudogap (corresponding to $m=2$ and 3 in the Bragg-Snell law) and due to light diffraction along directions different from the incident one [56, 57]. The final characteristic of the spectrum is the presence on its background of an extended Fabry-Perot-like interference fringes pattern indicative of the optical quality of the opals, which can be used to determine the sample thickness as soon as the $n_{\text {eff }}$ of the system is known [55]. In order to determine $n_{\text {eff }}$ angle resolved spectroscopy combined with a fitting procedure through (1) is useful (see below).

Indeed, it is well known that the opal photonic band structure depends both on the wave vector of light and its 


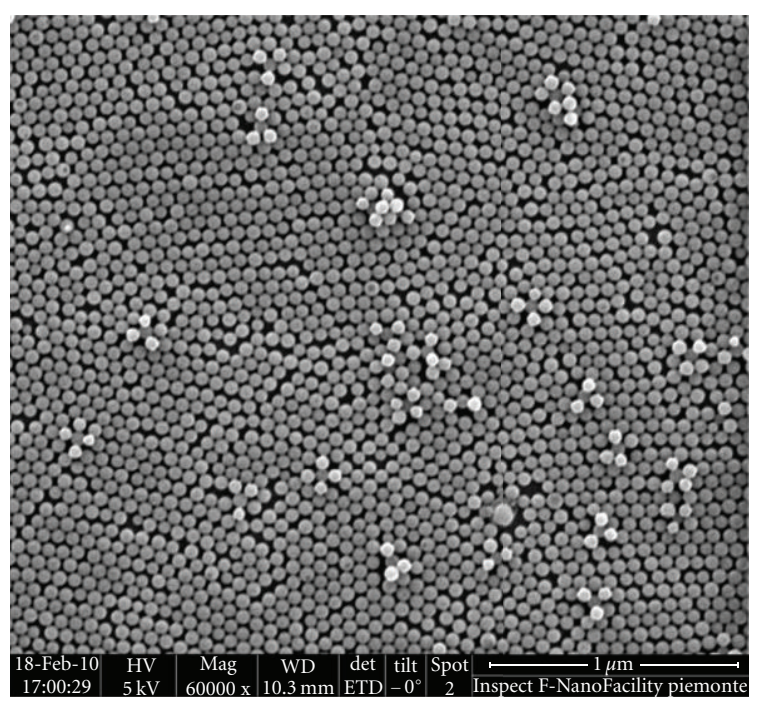

(a)

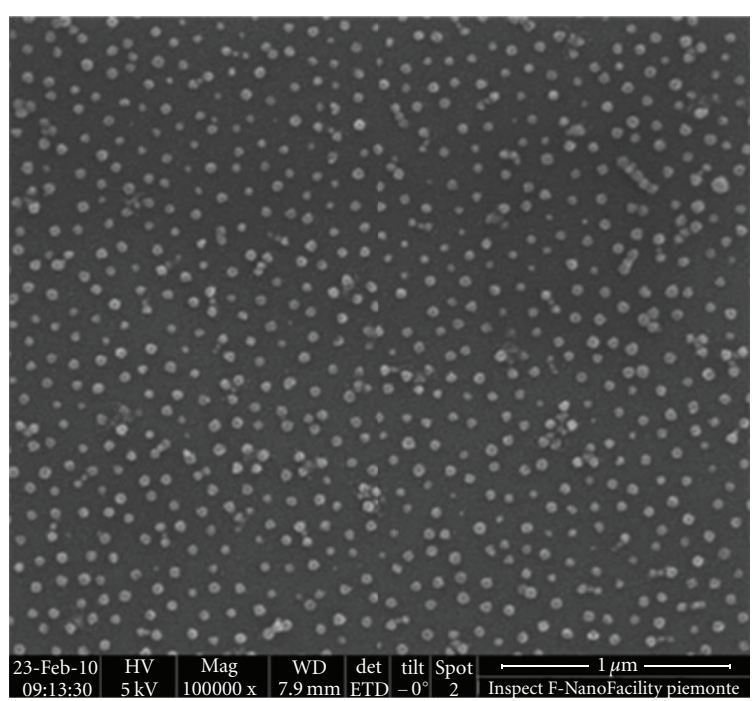

(b)

FIGURE 12: SEM micrographs of sample BPMS-3 after different RIE times: $0 \mathrm{~s}$ (a), $80 \mathrm{~s}$ (b) [32].

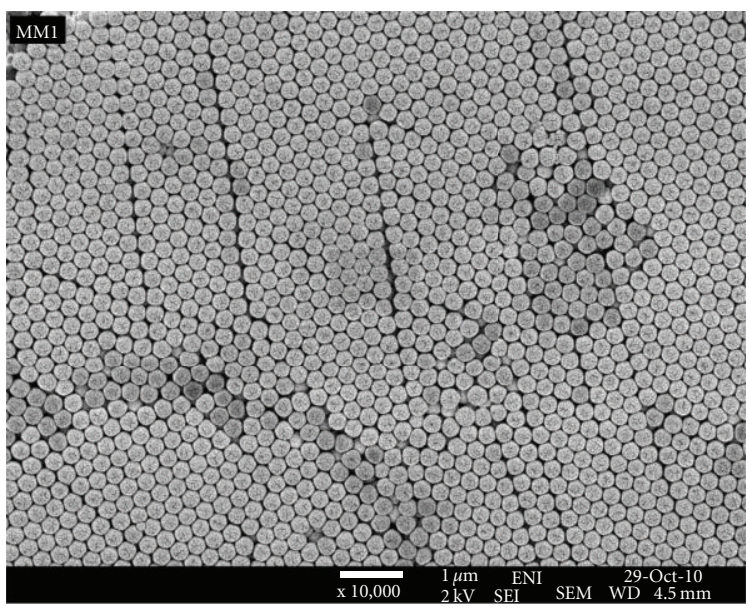

(a)

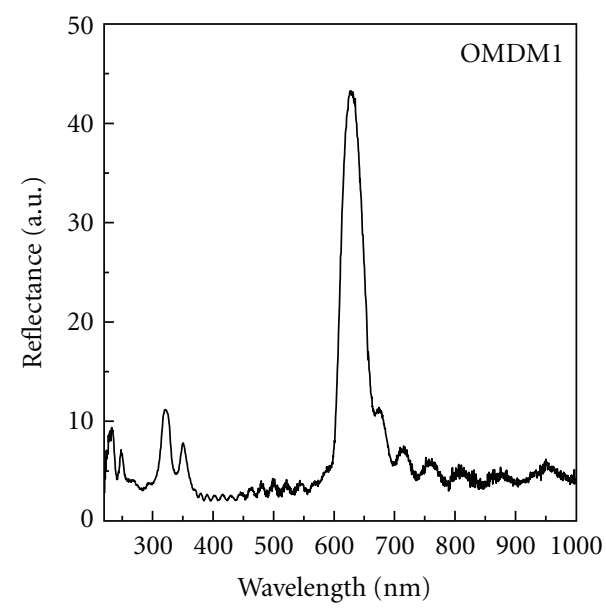

(b)

Figure 13: SEM micrograph (a) and reflectance spectrum of opal OMDM1 sample (b) [36].

polarization $[56,58,59]$. All these properties are also strongly dependent on the opal quality, which is a direct consequence of the monodispersity of colloids used for their growth. In order to probe the quality of the opals, a characterization of the opal by incidence-angle-dependent transmittance spectroscopy for both P (parallel to plane of incidence) and $S$ (perpendicular to the plane of incidence) polarization was performed. The advantage of the angular-dependent measurements is to clearly show the dispersive and polarized optical properties of the opals. In order to show these effects, in Figure 14 the transmittance spectra recorded at different incidence angles (from 0 to $54^{\circ}$ ) are reported for the OMDM1 opal for S (a) and P (b) polarization and with vertical orientation of the sample (vertical means that the direction of meniscus displacement during the growth is vertical with respect to the lab floor).
The stop band at $\theta=0^{\circ}$ is observed as a minimum at about $625 \mathrm{~nm}$, which shifts towards lower wavelengths upon increasing $\theta$. Upon fitting these data with (1) and by assuming that the interplanar spacing is determined only by the sphere diameter, a value of $n_{\text {eff }}=1.32$ is obtained [36].

At about $350 \mathrm{~nm}$, an additional structure having an opposite dispersion is instead observed, merging at about $40^{\circ}$ with that of the main stop band and then crossing it. Additional structures, almost dispersiveless, are also observed below $400 \mathrm{~nm}$. These complicate dispersive structures are strongly dependent on light polarization (more evident for $\mathrm{P}$ polarization) but are not characteristic of the nanosphere material since already observed for both polystyrene [56] and silica opals [60]. Finally, we notice that the full width at half maximum (FWHM) of the stop band becomes slightly anisotropic upon increasing the incidence angle. All these 


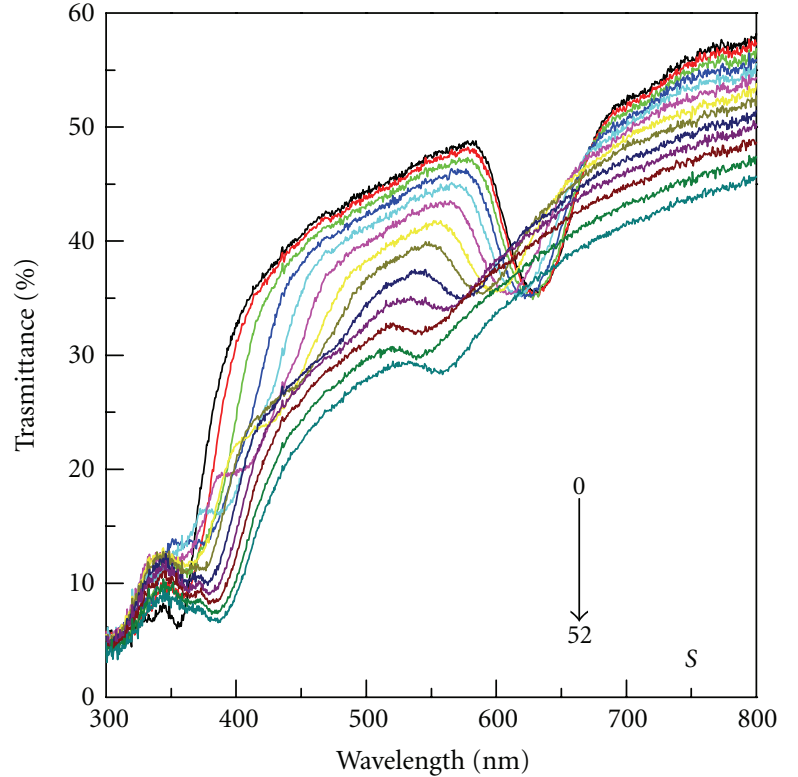

$\begin{array}{ll}- & 0 \\ - & 4 \\ - & 12 \\ - & 16 \\ - & 20 \\ - & 24 \\ - & 28\end{array}$

(a)
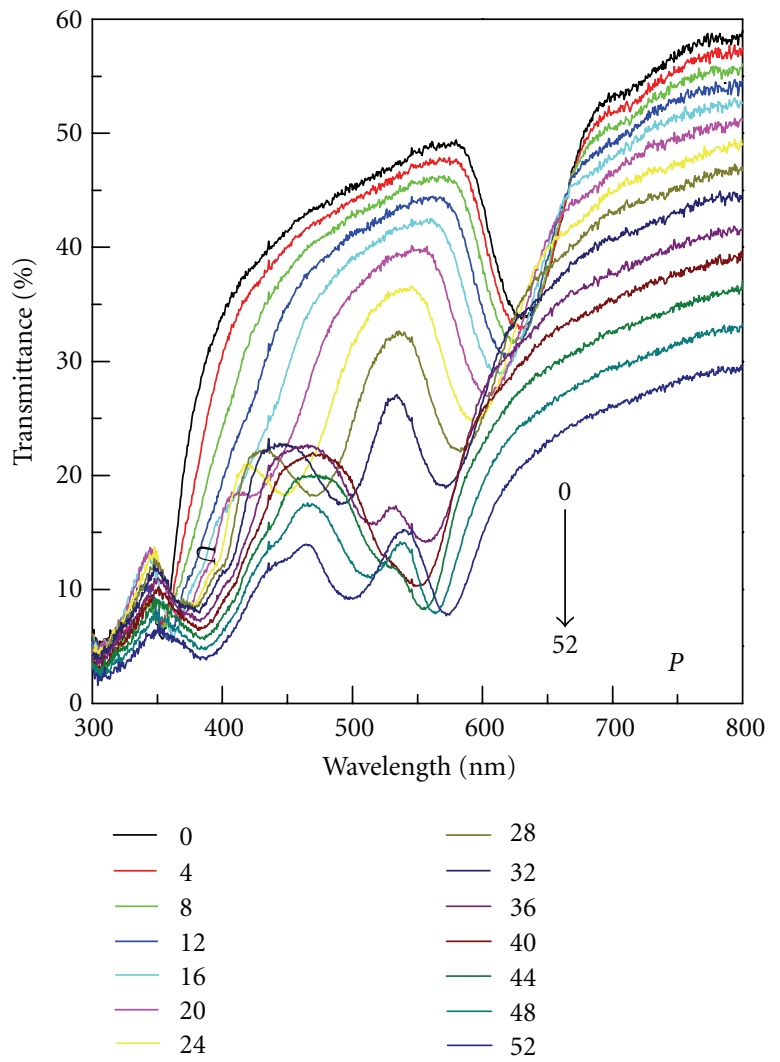

(b)

FIGURE 14: Transmittance spectra of OMDM1 opal as a function of the incidence angle from 0 to $52^{\circ}$ for S (a) and P (b) polarized light [36].

features are in full agreement with theoretical calculations $[56,60]$ thus demonstrating the high optical quality of these opals and, as a consequence, of polymer nanospheres [36].

\section{Conclusion}

Polytetrafluoroethylene (PTFE) latexes with particles in the submicrometer size range can be successfully employed as seeds in the emulsifier-free emulsion polymerization of various monomers including styrene, acrylic mixture, or methyl methacrylate or thus leading to a wide variety of core-shell nanosphere architectures. The seeded surfactantfree emulsion polymerization technique reveals an efficient process to prepare monodisperse latexes because the final number of particles was nearly the same as the initial number of seed particles thus allowing the final particle size to be precisely controlled leading to the target particle size with excellent reproducibility. In addition, a self sharpening of the size distribution was also observed with increasing the monomer to seed ratio. As a consequence of the high PTFE compartmentalization, a fractionated crystallization behaviour was observed in which the only PTFE crystallization process occurs at very high undercooling, possibly deriving from the homogeneous nucleation mechanism.

These core-shell particles can be employed as very efficient additives able to provide blends featuring a perfect dispersion of PTFE particles provided that the shell is constituted by the same polymeric material with which the polymer matrix is made up. In addition, due to the excellent control over the particle size and distribution, these nanoparticles are excellent building blocks for colloidal crystals and other nanostructured materials. In particular, 2D colloidal crystal of spheres leads to the smallest 2D nanostructuration for the preparation of masks with a combination of nanosphere lithography and reactive ion etching. 3D colloidal crystals were also obtained featuring excellent opal quality, which is a direct consequence of the monodispersity of colloids used for their growth.

\section{Acknowledgment}

Part of this work has been performed at NanoFacility Piemonte, INRiM, a laboratory supported by Compagnia di San Paolo.

\section{References}

[1] E. Giannetti and M. Visca, "Process for the polymerization in aqueous dispersion of fluorinated monomers," US Patent, 4864006, 1987.

[2] V. Kapeliouchko, E. Marchese, and P. Colaianna, “TFE polymerization process," EU Patent, 969027.

[3] G. Gozzi, "Halogenated butyl rubber," US Patent, 4632963, 1987. 
[4] M. Albano, M. Apostolo, V. Arcella, and E. Marchese, "Fluoroelastomer compositions," US Patent, 6395834, 2002.

[5] A. E. Feiring, J. F. Imbalzano, and D. L. Kerbow, "Advances in fluoroplastics," Plastics Engineering, vol. 27, 1994.

[6] J. Scheirs, Modern Fluoropolymers, John Wiley \& Sons, New York, NY, USA, 1997.

[7] B. Zhao, W. J. Brittain, and E. A. Vogler, "Trichlorosilane chemisorption on surface-modified poly(tetrafluoroethylene)," Macromolecules, vol. 32, no. 3, pp. 796-800, 1999.

[8] L. Y. Ji, E. T. Kang, K. G. Neoh, and K. L. Tan, "Oxidative graft polymerization of aniline on PTFE films modified by surface hydroxylation and silanization," Langmuir, vol. 18, no. 23, pp. 9035-9040, 2002.

[9] E. Akinay and T. Tincer, "Radiation grafting of vinyl monomers onto poly(tetrafluoroethylene) powder produced by $\gamma$ irradiation and properties of grafted poly(tetrafluoroethylene) filled low density polyethylene," Journal of Applied Polymer Science, vol. 79, no. 5, pp. 816-826, 2001.

[10] U. Konig, M. Nitschke, A. Menning et al., "Durable surface modification of poly(tetrafluoroethylene) by low pressure $\mathrm{H}_{2} \mathrm{O}$ plasma treatment followed by acrylic acid graft polymerization," Colloids and Surfaces B, vol. 24, no. 1, pp. 63-71, 2002.

[11] L. Häußler, G. Pompe, D. Lehmann, and U. Lappan, "Fractionated crystallization in blends of functionalized poly(tetrafluoroethylene) and polyamide," Macromolecular Symposia, vol. 164, no. 1, pp. 411-419, 2001.

[12] G. Pompe, L. Häußler, P. Pötschke et al., "Reactive polytetrafluoroethylene/polyamide compounds. I. Characterization of the compound morphology with respect to the functionality of the polytetrafluoroethylene component by microscopic and differential scanning calorimetry studies," Journal of Applied Polymer Science, vol. 98, no. 3, pp. 1308-1316, 2005.

[13] G. Pompe, L. Häußler, G. Adam et al., "Reactive polytetrafluoroethylene/polyamide 6 compounds. II. Study of the reactivity with respect to the functionality of the polytetrafluoroethylene component and analysis of the notched impact strength of the polytetrafluoroethylene/polyamide 6 compounds," Journal of Applied Polymer Science, vol. 98, no. 3, pp. 1317-1324, 2005.

[14] M. Okaniwa, "Synthesis of poly(tetrafluoroethylene)/poly(butadiene) core-shell particles and their graft copolymerization," Journal of Applied Polymer Science, vol. 68, no. 2, pp. 185-190, 1998.

[15] J. Othegraven, R. Piazza, and E. Bartsch, "Synthesis and characterization of core-shell colloids with fluorocarbon cores," Macromolecular Symposia, vol. 151, no. 1, pp. 515-520, 2000.

[16] X. Cui, S. Zhong, H. Zhang, Q. Gu, J. Li, and H. Wang, "Preparation and characterization of polytetrafluoroethylenepolyacrylate core-shell nanoparticles," Polymers for Advanced Technologies, vol. 18, no. 7, pp. 544-548, 2007.

[17] K. I. Suresh, T. Pakula, and E. Bartsch, "Synthesis morphology and rheological behavior of fluoropolymer-polyacrylate nanocomposites," Macromolecular Reaction Engineering, vol. 1, no. 2, pp. 253-262, 2007.

[18] R. Arshady, "Suspension, emulsion, and dispersion polymerization: a methodological survey," Colloid \& Polymer Science, vol. 270, no. 8, pp. 717-732, 1992.

[19] C. S. Chern, Principles and Applications of Emulsion Polymerization, John Wiley \& Sons, New York, NY, USA, 2008.

[20] Y. Xia, B. Gates, Y. Yin, and Y. Lu, "Monodispersed colloidal spheres: old materials with new applications," Advanced Materials, vol. 12, no. 10, pp. 693-713, 2000.

[21] O. Kalinina and E. Kumacheva, "Polymeric nanocomposite material with a periodic structure," Chemistry of Materials, vol. 13, no. 1, pp. 35-38, 2001.
[22] C. Paquet and E. Kumacheva, "Nanostructured polymers for photonics," Materials Today, vol. 11, no. 4, pp. 48-56, 2008.

[23] U. Jeong, Y. Wang, M. Ibisate, and Y. Xia, "Some new developments in the synthesis, functionalization, and utilization of monodisperse colloidal spheres," Advanced Functional Materials, vol. 15, no. 12, pp. 1907-1921, 2005.

[24] J. C. Hulteen and R. P. Van Duyne, "Nanosphere lithography: a materials general fabrication process for periodic particle array surfaces," Journal of Vacuum Science and Technology A, vol. 13, no. 3, pp. 1553-1558, 1995.

[25] K. Inoue and K. Kazuo, Photonic Crystals Physics, Fabrication and Applications, vol. 94 of Ohtaka editor Springer Series in Optical Sciences, Springer, Berlin, Germany, 2004.

[26] C. S. Chern, "Emulsion polymerization mechanisms and kinetics," Progress in Polymer Science, vol. 31, no. 5, pp. 443486, 2006.

[27] J. W. Goodwin, J. Hearn, C. C. Ho, and R. H. Ottewill, "Studies on the preparation and characterisation of monodisperse polystyrene laticee - III. Preparation without added surface active agents," Colloid and Polymer Science Kolloid Zeitschrift \& Zeitschrift für Polymere, vol. 252, no. 6, pp. 464-471, 1974.

[28] J. W. Goodwin, H. R. Ottewill, R. Pelton, G. Vianello, and D.E. Yates, "Control of particle size in the formation of polymer lattices," British Polymer Journal, vol. 10, no. 3, pp. 173-180, 1978.

[29] M. Egen and R. Zentel, "Surfactant-free emulsion polymerization of various methacrylates: towards monodisperse colloids for polymer opals," Macromolecular Chemistry and Physics, vol. 205, no. 11, pp. 1479-1488, 2004.

[30] B. Lange, N. Metz, M. N. Tahir et al., "Functional polymeropals from core-shell colloids," Macromolecular Rapid Communications, vol. 28, no. 20, pp. 1987-1994, 2007.

[31] E. Giani, K. Sparnacci, M. Laus, G. Palamone, V. Kapeliouchko, and V. Arcella, "PTFE-polystyrene core-shell nanospheres and nanocomposites," Macromolecules, vol. 36, no. 12 , pp. 4360-4367, 2003.

[32] K. Sparnacci, D. Antonioli, S. Deregibus et al., "Twodimensionalnon-close-packed arrays of nanoparticles via core-shell nanospheres and reactive ion etching," Polymers for Advanced Technologies. In press.

[33] K. Sparnacci, D. Antonioli, S. Deregibus et al., "PTFE-based core-soft shell nanospheres and soft matrix nanocomposites," Macromolecules, vol. 42, no. 10, pp. 3518-3524, 2009.

[34] V. Kapeliouchko, G. Palamone, T. Poggio et al., "PMMA-based core-shell nanoparticles with various PTFE cores," Journal of Polymer Science A, vol. 47, no. 11, pp. 2928-2937, 2009.

[35] D. Antonioli, S. Deregibus, K. Sparnacci et al., "Fine tuning of the size of PTFE-PMMA core-shell nanospheres," Polymers for Advanced Technologies, vol. 23, no. 3, pp. 558-564, 2012.

[36] D. Antonioli, S. Deregibus, G. Panzarasa et al., "PTFE-PMMA core-shell nanoparticles as building blocks for self-assembled opals: synthesis, properties and optical response," Polymer International. In press.

[37] J. Rybczynski, U. Ebels, and M. Giersig, "Large-scale, 2D arrays of magnetic nanoparticles," Colloids and Surfaces A, vol. 219, pp. 1-6, 2003.

[38] A. Kosiorek, W. Kandulski, H. Glaczynska, and M. Giersig, "Fabrication of nanoscale rings, dots, and rods by combining shadow nanosphere lithography and annealed polystyrene nanosphere masks," Small, vol. 1, no. 4, pp. 439-444, 2005.

[39] S. M. Weekes, F. Y. Ogrin, W. A. Murray, and P. S. Keatley, "Macroscopic arrays of magnetic nanostructures from selfassembled nanosphere templates," Langmuir, vol. 23, no. 3, pp. 1057-1060, 2007. 
[40] P. Jiang, J. F. Bertone, and V. L. Colvin, "A lost-wax approach to monodisperse colloids and their crystals," Science, vol. 291, no. 5503, pp. 453-457, 2001.

[41] L. Berti, M. Cucini, F. Di Stasio et al., "Spectroscopic investigation of artificial opals infiltrated with a heteroaromatic quadrupolar dye," Journal of Physical Chemistry C, vol. 114, no. 6, pp. 2403-2413, 2010.

[42] S. M. Heard, F. Grieser, C. G. Barraclough, and J. V. Sanders, "The characterization of ag sols by electron microscopy, optical absorption, and electrophoresis," Journal of Colloid And Interface Science, vol. 93, no. 2, pp. 545-555, 1983.

[43] S. Jiang, E. D. Sudol, V. L. Dimonie, and M. S. El-Aasser, "Seeding as a means of controlling particle size in dispersion polymerization," Journal of Applied Polymer Science, vol. 108, no. 6, pp. 4096-4107, 2008.

[44] X. Q. Wang, D. R. Chen, J. C. Han, and S. Y. Du, "Crystallization behavior of polytetrafluoroethylene (PTFE)," Journal of Applied Polymer Science, vol. 83, no. 5, pp. 990-996, 2002.

[45] M. Laus, K. Sparnacci, D. Antonioli et al., "On the multiple crystallization behavior of PTFE in PMMA/PTFE nanocomposites from core-shell nanoparticles," Journal of Polymer Science B, vol. 48, no. 5, pp. 548-554, 2010.

[46] J. A. Koutsky, A. G. Walton, and E. Baer, "Nucleation of polymer droplets," Journal of Applied Physics, vol. 38, no. 4, pp. 1832-1839, 1967.

[47] V. Everaert, G. Groeninckx, and L. Aerts, "Fractionated crystallization in immiscible $\mathrm{POM} /(\mathrm{PS} / \mathrm{PPE})$ blends part 1: effect of blend phase morphology and physical state of the amorphous matrix phase," Polymer, vol. 41, no. 4, pp. 1409$1428,2000$.

[48] V. Balsamo and L. M. Gouveia, "Interplay of fractionated crystallization and morphology in polypropylene/polyte-( $\varepsilon$ caprolactone) blends," Journal of Polymer Science B, vol. 45, no. 11, pp. 1365-1379, 2007.

[49] H. L. Chen, J. C. Wu, T. L. Lin, and J. S. Lin, "Crystallization kinetics in microphase-separated poly(ethylene oxide)-blockpoly(1, 4-butadiene)," Macromolecules, vol. 34, no. 20, pp. 6936-6944, 2001.

[50] J. Pavlinec, M. Lazar, and K. Csomorova, “Thermal degradation of multilayer methacrylate-acrylate particle-bead polymer powders and melts," Polymer Degradation and Stability, vol. 55 , no. 1 , pp. $65-71,1997$.

[51] B. J. Holland and J. N. Hay, "The kinetics and mechanisms of the thermal degradation of poly(methyl methacrylate) studied by thermal analysis-Fourier transform infrared spectroscopy," Polymer, vol. 42, no. 11, pp. 4825-4835, 2001.

[52] D. Antonioli, M. Laus, K. Sparnacci et al., "Thermal and DMA characterization of PTFE-PMMA nanocomposites from coreshell nanoparticles," Macromolecular Symposia, vol. 296, no. 1, pp. 197-202, 2010.

[53] Y. J. Zhang, W. Li, and K. J. Chen, "Application of twodimensional polystyrene arrays in the fabrication of ordered silicon pillars," Journal of Alloys and Compounds, vol. 450, no. 1-2, pp. 512-516, 2008.

[54] J. D. Joannopulos, R. D. Meade, and J. N. Win, Photonic Crystals: Molding the Flow of the Light, Princeton University Press, Princeton, NJ, USA, 1995.

[55] V. Morandi, F. Marabelli, V. Amendola, M. Meneghetti, and D. Comoretto, "Colloidal photonic crystals doped with gold nanoparticles: spectroscopy and optical switching properties," Advanced Functional Materials, vol. 17, no. 15, pp. 2779-2786, 2007.

[56] E. Pavarini, L. C. Andreani, C. Soci, M. Galli, F. Marabelli, and D. Comoretto, "Band structure and optical properties of opal photonic crystals," Physical Review B, vol. 72, no. 4, pp. 1-10, 2005.

[57] L. C. Andreani, A. Balestreri, J. F. Galisteo-López et al., "Optical response with three-fold symmetry axis on oriented microdomains of opal photonic crystals," Physical Review B, vol. 78, no. 20, pp. 205304-205311, 2008.

[58] J. F. Galisteo-Lopez, F. Lopez-Tejeira, S. Rubio, C. Lopez, and J. Sanchez-Dehesa, "Experimental evidence of polarization dependence in the optical response of opal-based photonic crystals," Applied Physics Letters, vol. 82, no. 23, pp. 4068-4070, 2003.

[59] F. Lopez-Tejeira, T. Ochiai, K. Sakoda, and J. SanchezDehesa, "Symmetry characterization of eigenstates in opalbased photonic crystals," Physical Review B, vol. 65, no. 19, pp. 195110-195118, 2002.

[60] D. Comoretto, D. Cavallo, G. Dellepiane et al., "Optical studies of artificial opals as 3D photonic crystals," Material Research Society Symposium Proceeding, vol. 708, no. 1, pp. 1-6, 2002. 

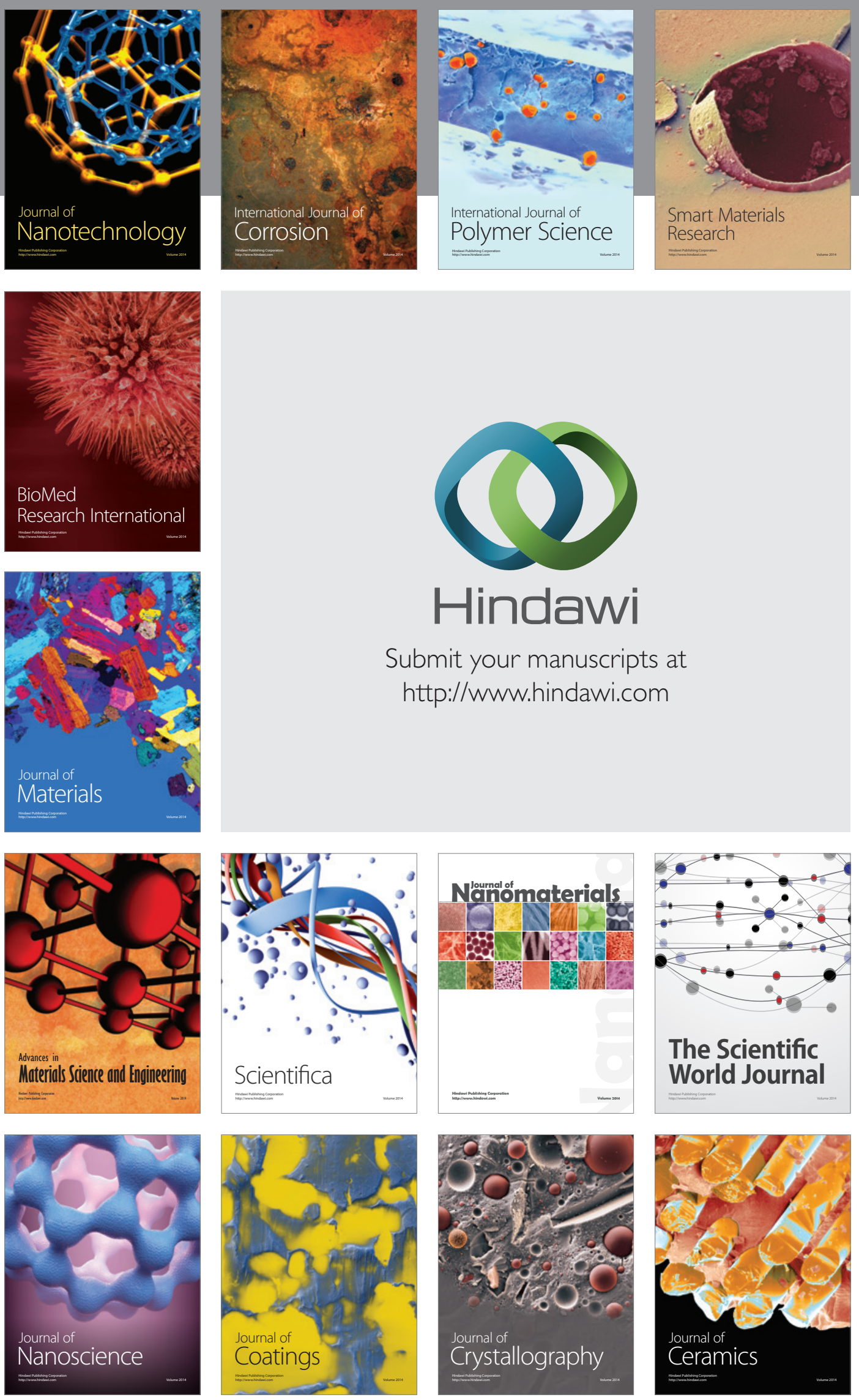

The Scientific World Journal

Submit your manuscripts at

http://www.hindawi.com

\section{World Journal}

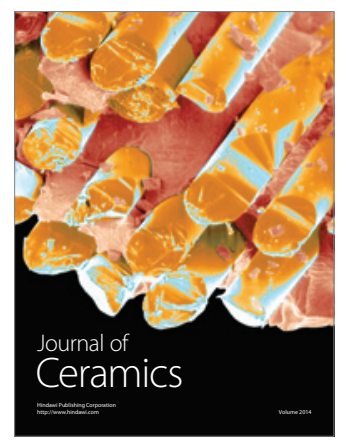

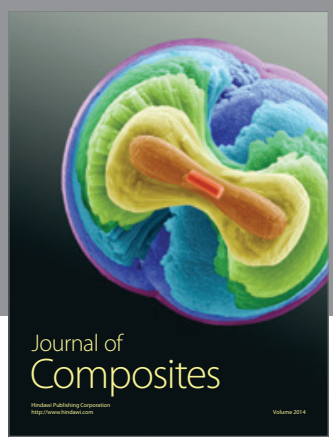
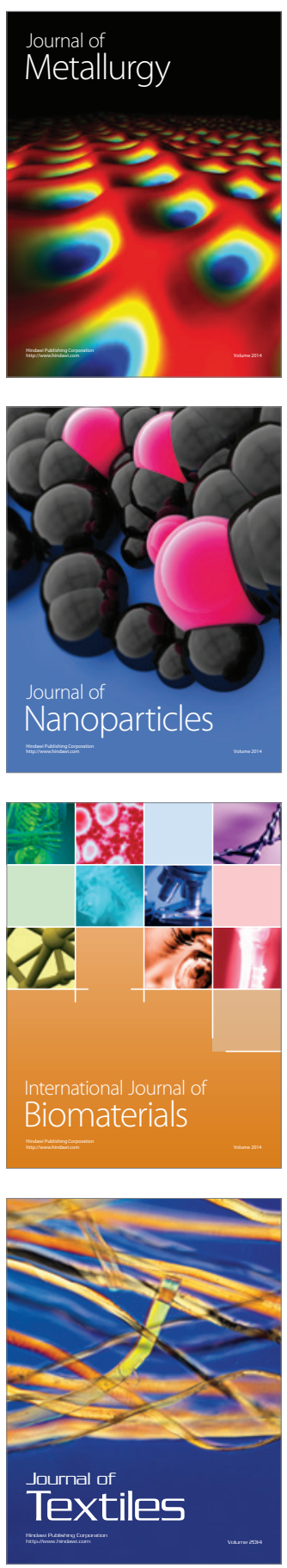